This is the peer reviewed accepted manuscript of the following article:

Ortalli M, llari A, Colotti G, De Ionna I, Battista T, Bisi A, Gobbi S, Rampa A, Di Martino RMC, Gentilomi GA, Varani S, Belluti F. Identification of chalcone-based antileishmanial agents targeting trypanothione reductase. Eur J Med Chem. 2018 May 25;152:527-541.

Final peer reviewed version available at: https://doi.org/10.1016/j.jmech.2018.04.057

Rights / License:

The terms and conditions for the reuse of this version of the manuscript are specified in the publishing policy. For all terms of use and more information see the publisher's website.

This item was downloaded from IRIS Università di Bologna (https://cris.unibo.it/)

When citing, please refer to the published version. 


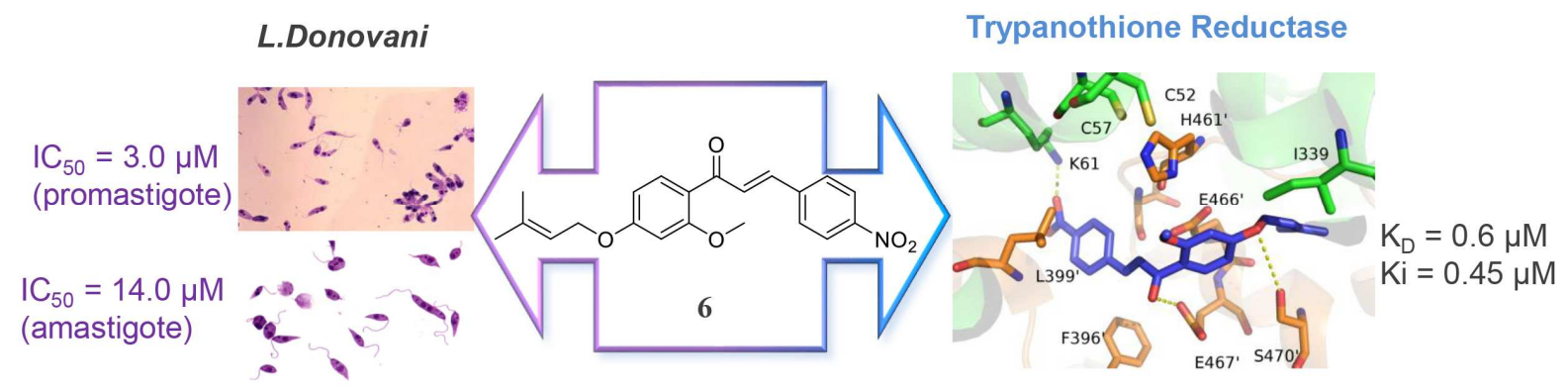




\section{Identification of Chalcone-based Antileishmanial Agents Targeting Trypanothione}

\section{Reductase}

Margherita Ortalli ${ }^{1}$, Andrea Ilari $^{2}$, Gianni Colotti ${ }^{2}$, Ilenia De Ionna ${ }^{3}$, Theo Battista ${ }^{3}$, Alessandra Bisi $^{4}$, Silvia Gobbi ${ }^{4}$, Angela Rampa ${ }^{4}$, Rita M. C. Di Martino ${ }^{4 \S}$, Giovanna A. Gentilomi ${ }^{4}$, Stefania (1) $\operatorname{Varani}^{1,5} \wedge$ and Federica Belluti ${ }^{4} \wedge *$

${ }^{1}$ Department of Experimental, Diagnostic and Specialty Medicine, Alma Mater Studiorum University of Bologna, Bologna, Italy

${ }^{2}$ CNR-Institute of Molecular Biology and Pathology, Rome, Italy

${ }^{3}$ Department of Biochemical Sciences "A. Rossi Fanelli”, Sapienza University, Rome, Italy

${ }^{4}$ Department of Pharmacy and Biotechnology, Alma Mater Studiorum University of Bologna,

Bologna, Italy. ${ }^{\S}$ Present address: Department. of Drug Discovery and Development, Istituto

Italiano di Tecnologia,via Morego n.30, 16163 Genova, Italy

${ }^{5}$ Unit of Clinical Microbiology, Regional Reference Centre for Microbiological Emergencies

(CRREM), St. Orsola-Malpighi University Hospital, Bologna, Italy

$\wedge$ these authors contributed equally to this work

20 *Corresponding author: federica.belluti@unibo.it

Abstract

3 All currently used first-line and second-line drugs for the treatment of leishmaniasis exhibit several drawbacks including toxicity, high costs and route of administration. Furthermore, some drugs are associated with the emergence of drug resistance. Thus, the development of new treatments for leishmaniasis is a priority in the field of neglected tropical diseases. The present work highlights the 
use of natural derived products, i.e. chalcones, as potential source of antileishmanial agents. Thirtyone novel chalcone compounds have been synthesized and their activity has been evaluated against promastigotes of Leishmania donovani; 16 compounds resulted active against L. donovani in a range from 3.0 to $21.5 \mu \mathrm{M}$, showing low toxicity against mammalian cells. Among these molecules, 6 and 16 showed good inhibitory activity on both promastigotes and intracellular amastigotes, coupled with an high selectivity index. Furthermore, compounds $\mathbf{6}$ and $\mathbf{1 6}$ inhibited the promastigote growth of other leishmanial species, including L. tropica, L. major and L. infantum. Finally, $\mathbf{6}$ and $\mathbf{1 6}$ interacted with high affinity with trypanothione reductase (TR), an essential enzyme for the leishmanial parasite and compound $\mathbf{6}$ inhibited TR with sub-micromolar potency. Thus, the effective inhibitory activity against Leishmania, the lack of toxicity on mammalian cells and the ability to block a crucial parasite's enzyme, highlight the potential for compound $\mathbf{6}$ to be optimized as novel drug candidate against leishmaniasis.

\section{Keywords}

Chalcone, drug discovery, leishmaniasis, natural products, neglected tropical disease, trypanothione reductase

\section{INTRODUCTION}

Leishmaniases are vector-borne infections caused by protozoan parasites belonging to the genus Leishmania that are transmitted through the bite of phlebotomine sand flies of the genus Phlebotomus in the Old World [1]. Most forms of the diseases are zoonotic and only 21 of the 30 Leishmania species that infect mammals may cause human infection.

Most infections caused by Leishmania parasites are asymptomatic, but in symptomatic patients clinical manifestations range from cutaneous leishmaniasis (CL), which may result in disfiguring 
scars if left untreated, to the potentially fatal visceral leishmaniasis (VL), which is characterized by fever, splenomegaly, pancytopenia and weight loss [2].

Leishmaniases are distributed in Asia, Africa, Latin America and Southern Europe, with an estimation of 1.5-2.0 million new cases per year of CL and 0.5 million cases of VL [3]. Despite this, leishmaniases are classified among the most neglected diseases, based on their strong association with poverty and on the limited resources invested in their diagnosis, treatment and control [2]. Chemotherapy is the only method for protection against leishmaniasis, since there is currently no approved vaccine for humans [4]. Treatment of leishmaniasis comprises liposomal amphotericin B, pentavalent antimonials, paromomycin and miltefosine; these drugs are plagued by several limitations including high costs, toxicity, route of administration and poor efficacy [5]. Moreover, the increasing emergence of Leishmania parasites that are resistant to antimonial drugs is a serious problem in several endemic regions [6]. This scenario emphasizes the need of developing novel effective, safe and economically feasible antileishmanial agents.

The implementation of the genome project for many trypanosomatid species lead to the identification of several drug targets suitable for gaining parasite selective inhibition [7]. Indeed, targeting a unique and essential parasite metabolic pathway, which is absent in mammals is generally considered a successful therapeutic strategy.

In this context, the thiol-dependent redox polyamine metabolism represents an essential detoxifying system by means of which the parasite eliminates its toxic endogenous metabolites [8]. While the mammalian redox defense machinery is based on glutathione $(\mathrm{GSH})$, the protozoan parasites from the Trypanosomatidae family, including Trypanosoma and Leishmania, strictly depend on a different pathway for supporting their intracellular redox homeostasis; they employ trypanothione (N1,N8-bis-glutathionyl-spermidine) in its reduced thiol form $\mathrm{T}(\mathrm{SH})_{2}$ [9]. Trypanothione disulfide $\left(\mathrm{TS}_{2}\right)$ is obtained by means of two consecutive steps, each involving the conjugation of GSH to $\mathrm{N}_{1}$ and $\mathrm{N}_{8}$ amino groups of spermidine by the ATP-dependent C-N ligase trypanothione synthetase (TryS). Trypanothione reductase (TR), a NADPH-dependent flavoprotein, 
reduces $\mathrm{TS}_{2}$ to $\mathrm{T}(\mathrm{SH})_{2}$, thus ensuring an intracellular reducing environment. The inhibition of TryS and/or TR is known to disrupt the parasite redox balance $[10,11]$; these two enzymes can be regarded as validated molecular targets for the development of effective and selective antileishmanial drugs $[9,12]$.

TR inhibition may be achieved by competing with trypanothione binding to the active site; for example, trivalent antimony $\mathrm{Sb}(\mathrm{III})$, the active form of the antimonial drug sodium stibogluconate (SSG) [13], a number of metals, such as $\mathrm{Ag}(\mathrm{I})$ and $\mathrm{Au}(\mathrm{I})$ [14-16] and some TR inhibitors, such as azole and diaryl compounds $[17,18]$ have been reported to directly bind the trypanothione binding site.

Natural products (NPs) including flavonoids, isoflavonoids, saponins, alkaloids, tannins and indoles have been shown to exert antileishmanial effects $[19,20]$. Among them, chalcones (1,3diaryl-2-propen-1-ones), prominent secondary metabolites and precursors of flavonoids, can be considered "privileged structures", i.e. evolutionary-chosen molecules that have evolved to achieve an inherent affinity for diverse biological macromolecules in the natural selection process [21]. Indeed, chalcones display a wide range of pharmacological effects, including antioxidant, antimutagenic, antimitotic, antimetastatic and antiinflammatory activity [22, 23]. The antileishmanial potential of chalcones has also been demonstrated [20]; naturally occurring chalcones such as licochalcone A and isocordoin (Figure 1), isolated from Glycyrrhiza glabra and Lonchocarpus xuul, respectively, were able to efficiently inhibit the proliferation of different Leishmania species [24-26]. Unfortunately, the intrinsic cytotoxicity of these molecules may represent an undesired aspect. In this study, the chalcone framework was selected as main scaffold to develop a new series of effective and safe antileishmanial agents and targeting a key enzyme in the polyamine-trypanothione pathway, ie TR. 


\section{RESULTS}

\subsection{Design strategy}

A small library of 31 chalcone-based analogues was designed and synthesized (Figure 1). In particular, the A-ring of the main scaffold was properly functionalized at the positions 2 and 4: the

C-4 position was occupied by a suitable alkoxy function (O-R), namely 3,3-dimethylallyoxy (or prenyloxy) and propargyloxy affording Series 1 and 2, respectively. The C-2 position was differently functionalized by introduction of hydroxy, methoxy, prenyloxy and propargyloxy groups $\left(\mathrm{O}-\mathrm{R}_{1}\right)$. In order to perform a Structure Activity Relationship (SAR) study, different moieties were introduced as B-ring, namely pyridine or aryl functions bearing methoxy, bromo, nitro, and fluorine substituents.

\subsection{Synthesis}

All the tested chalcones were readily synthesized through the classic base-catalyzed ClaisenSchmidt procedure (as shown in Scheme 1). In details, the selected acetophenone was reacted at room temperature with the appropriate aldehyde in ethyl alcohol and in the presence of a $50 \%$ $\mathrm{KOH} / \mathrm{H}_{2} \mathrm{O}$ solution, to give the desired final compounds (1-31, Table 1). The acetophenone intermediates were obtained by reaction of 2,4-dihydroxyacetophenone with the appropriate alkyl halide to obtain the 2-OH,4-alkoxyacetophenones $(\mathbf{3 2}, \mathbf{3 3})$ and 2,4-bi-functionalyzed-acetophenones (34-37).

\subsection{Biological and Enzymatic Assays}

First, 31 chalcone-based derivatives were investigated for their antileishmanial effect on the promastigotes of L. donovani. Then, for 16 analogues that inhibited parasite growth at micromolar level, cytotoxicity against mammalian kidney epithelial cells and affinity for TR enzyme (SPRbased assay) were also evaluated. This allowed us to identify two promising molecules in terms of activity and selectivity that were then further investigated for their ability to inhibit promastigote 
growth of different parasitic species, including L.tropica, L.major and L.infantum and to affect the growth L.donovani amastigotes. Finally, the mechanism of TR inhibition was also studied.

\subsubsection{In vitro inhibition of Leishmania promastigote growth}

To assess the antileishmanial potential of the synthesized compounds, a reference strain of $L$. donovani (MHOM/NP/02/BPK282/0cl4) was employed in two different stages of the parasitic life cycle; the extracellular promastigote form is found in the sandfly vector, while intracellular amastigote form is specifically found in the host cell.

In a first experiment, 31 chalcone-based derivatives were investigated for their antileishmanial efficacy on the promastigote forms of L. donovani (Table 1). Amphotericin B was employed as reference compound. Data were expressed as $\mathrm{IC}_{50}$, i.e. the concentration of compound that is required to inhibit growth by $50 \%$.

Among the tested chalcones, compounds 1-16 turned out to effectively inhibit the promastigote growth with micromolar potency and $\mathrm{IC}_{50} / 72 \mathrm{~h}$ values ranged from $21.5 \mu \mathrm{M}$ (compound 12) to 3.0 $\mu \mathrm{M}$ (compound 6). Concerning analogues 17-31, no antileishmanial effect was observed at the maximal dose of $40.0 \mu \mathrm{M}$ and were then discarded from further evaluation. Among derivatives with a simple phenyl function as B-ring included in Series $1(7, \mathbf{1 9 - 2 1})$, the substituent at the 2-position of the A-ring markedly affected the inhibitory behaviour against Leishmania. In details, compound 7, bearing a methoxy function, showed an $\mathrm{IC}_{50} / 72 \mathrm{~h}$ of $15.0 \mu \mathrm{M}$, while the presence of hydroxy, acethoxy, and prenyloxy (19, 20 and 21, respectively) rendered the derivatives almost inactive. By keeping the most favourable 2-methoxy-4-prenyloxy substitution pattern in the A-ring, further modifications were applied to the B-aryl ring. The presence of electron-donating moieties, such as methoxy groups, on several positions of the B-ring (compounds $\mathbf{8 , 2 3 , 2 4}$ ) gave different results, as only the bulky 3,4,5-trimethoxylated analogue 8 proved to inhibit parasite growth with an $\mathrm{IC}_{50} / 72 \mathrm{~h}$ of $11.0 \mu \mathrm{M}$. The effect of different electron-withdrawing groups, namely bromo, nitro, and fluoro, on the para position of the B-ring (compounds $\mathbf{5}, \mathbf{6}$, and 22, respectively) was also investigated: 
compound 6, with the nitro substituent, resulted to be the most active among the series, showing an $\mathrm{IC}_{50} / 72 \mathrm{~h}$ of $3.0 \mu \mathrm{M}$, followed by the bromo-derivative $5\left(\mathrm{IC}_{50} / 72 \mathrm{~h}=16.0 \mu \mathrm{M}\right)$. The introduction of a heterocyclic furyl group (18) led to a loss of activity, while a 4- and 3-pyridyl moiety (3 and $\mathbf{4}$, respectively) allowed to retain good activities $\left(\mathrm{IC}_{50} / 72 \mathrm{~h}=10.5 \mu \mathrm{M}\right)$. The corresponding pyridylbased analogues (1 and 2), characterized by a 2-hydroxyl function, retained leishmanicidal activity $\left(\mathrm{IC}_{50} / 72 \mathrm{~h}=5.0 \mu \mathrm{M}\right.$ and $8.5 \mu \mathrm{M}$, respectively).

A different trend of potency was observed in the 4-propargyloxylated Series 2 upon applying different B-ring functionalization. The insertion on B-ring of methoxy groups (27, 28 and 29-31) and para $-\mathrm{NO}_{2}$ functions (analogues 25 and 26) led to inactive compounds. Interestingly, the presence of a para-F phenyl B-ring and of a 2-propargyloxylated A-ring (compound 16) conferred an effective ability to inhibit Leishmania growth $\left(\mathrm{IC}_{50} / 72 \mathrm{~h}=12.5 \mu \mathrm{M}\right)$. Moreover, the para-Br derivatives 12 and $\mathbf{1 5}$ retained a moderate antileishmanial activity $\left(\mathrm{IC}_{50} / 72 \mathrm{~h}=21.5 \mu \mathrm{M}\right.$ and 15.0 $\mu \mathrm{M}$, respectively) that was comparable to the corresponding Br-derivative 5 of Series 1 . The pyridine-based analogues 10, 11, and 13, 14 with a 2-methoxy-4-propargyloxy and 2,4-bispropargyloxy A-ring, respectively, showed low micromolar potencies $\left(\mathrm{IC}_{50} / 72 \mathrm{~h}\right.$ values ranging from $4.0 \mu \mathrm{M}$ to $9.5 \mu \mathrm{M}$ ), similar to that of the corresponding Series 1 analogues (1-4). A reduction of activity was observed for compound 9, designed as the 2-hydroxy congener of 11 and 14 derivatives.

Compound $\mathbf{6}$ and $\mathbf{1 6}$ were further investigated for their antileishmanial efficacy on the promastigote forms of three other parasitic species, ie L. tropica, L. major and L. infantum. Interestingly, the results obtained highlight diverse susceptibilities of different parasitic species to the compounds., In detail, compound 6 exhibited an $\mathrm{IC}_{50} / 72 \mathrm{~h}$ of $5.2 \mu \mathrm{M}, 3.3 \mu \mathrm{M}$ and $1.6 \mu \mathrm{M}$ on L. tropica, L. major and $L$. infantum, respectively, while compound $\mathbf{1 6}$ showed an $\mathrm{IC}_{50} / 72 \mathrm{~h}$ of $13 \mu \mathrm{M}, 10 \mu \mathrm{M}$ and 1.6 $\mu \mathrm{M}$ on L. tropica, L. major and L. infantum, respectively. Thus, both compound $\mathbf{6}$ and $\mathbf{1 6}$ exhibited the highest inhibitory activity on $L$. infantum, revealing L. infantum as the most susceptible species to the examined chalcones. 


\subsubsection{In vitro mammalian cell toxicity}

The cytotoxic effect against mammalian cells was evaluated for the most active chalcones (1-16) by using Vero cell line (mammalian kidney epithelial cells) (Table 1). Data were expressed as 50\% cytotoxic concentration $\left(\mathrm{CC}_{50}\right)$. The tested compounds generally displayed moderate to low cytotoxicity, with $\mathrm{CC}_{50} / 72 \mathrm{~h}$ values above $30 \mu \mathrm{M}$. In particular, analogues $\mathbf{5}, \mathbf{6}$ and $\mathbf{1 6}$ were characterized by low toxicity, with cytotoxic effect detected only at $600 \mu \mathrm{M}$. On the contrary, the pyridine-based chalcones showed an unfavorable SI due to their moderate cytotoxic effects. It is noteworthy that $\mathrm{CC}_{50} / 72 \mathrm{~h}$ value of the reference compound amphotericin $\mathrm{B}$ was $200 \mu \mathrm{M}$, lower than those of compound $\mathbf{6}$ and 16. The cytotoxic effect against human acute monocytic leukemia cell line (THP-1) was also evaluated (Table 1) and the selectivity index (SI) was calculated as $\mathrm{CC}_{50} / \mathrm{IC}_{50}$ ratio. Analogue 5 showed a higher cytotoxic effect on THP-1 than on the Vero cell line. On the other hand, compound $\mathbf{6}$ and 16, the most promising of the series, showed the same low cytotoxic effect on the Vero cell line and on THP-1. The cytotoxicity assays allowed to identify compounds $\mathbf{6}$ and $\mathbf{1 6}$ as the most promising of the series. Indeed they showed a remarkable antileishmanial potency against the extracellular form of the parasite $\left(\mathrm{IC}_{50} / 72 \mathrm{~h}=3.0 \mu \mathrm{M}\right.$ and 12.5 $\mu \mathrm{M}$, for compound $\mathbf{6}$ and 16, respectively) that was coupled with a good SI on mammalian cells (200 and 48, for compound $\mathbf{6}$ and $\mathbf{1 6}$, respectively).

\subsubsection{Inhibition of L. donovani amastigote growth}

Considering the promising results obtained for $\mathbf{6}$ and 16, these compounds were selected to be tested for their efficacy against the amastigote stage of $L$. donovani. The amastigote assay was performed by using metacyclic promastigotes to infect differentiated THP-1 macrophagic cells; amastigotes transformed from metacyclic promastigotes proliferated inside host macrophages. An inversion of potencies was observed when focusing on inhibitory activity of 6 and 16 on amastigotes growth, with respect to activities recorded on promastigotes (Figure 2a- 
2b). Indeed, compound $\mathbf{1 6}$ exhibited a higher inhibitory effect on amastigotes than on promastigotes $\left(4.5 \mu \mathrm{M}\right.$ vs $12.5 \mu \mathrm{M}, \mathrm{IC}_{50} / 72 \mathrm{~h}$ calculated on amastigote and promastigote cultures, respectively), while compound $\mathbf{6}$ showed a lower potency on amastigotes than on promastigotes (14.0 $\mu \mathrm{M}$ vs $3.0 \mu \mathrm{M}, \mathrm{IC}_{50} / 72 \mathrm{~h}$ detected on amastigote and promastigote cultures, respectively).

\subsubsection{Evaluation of activity toward trypanothione reductase}

\subsubsection{Surface Plasmon Resonance screening}

For Surface Plasmon Resonance (SPR) experiments, TR from Leishmania spp. has been immobilized by amine coupling on COOH5 sensorchips, while chalcones were analytes; FastStep SPR experiments were performed by stepped analyte gradient injections (ranging between 1.5 and $100 \mu \mathrm{M})$. Screening of the 16 most active chalcones (compounds 1-16) demonstrated that two molecules, compounds $\mathbf{6}$ and 16, interacted directly and with high affinity with TR. $K_{D}$ values calculated for these compounds were $\mathrm{K}_{\mathrm{D}}$ (compound 6) $=0.6 \pm 0.2 \mu \mathrm{M}$ and $\mathrm{K}_{\mathrm{D}}($ compound 16) $=2.4$ $\pm 0.5 \mu \mathrm{M}$ (Figure 3).

\subsubsection{Enzymatic assays}

Kinetic studies were performed on compound $\mathbf{6}$, endowed with the highest activity against the Each line in the Dixon plot represents linear regression analysis of reciprocal of average fitted rates of $\mathrm{TS}_{2}$ reduction for different substrate concentrations, as a function of inhibitor concentration. The promastigote forms of L. donovani and affinity toward TR. Steady state kinetic experiments were carried out at various concentrations of $\mathrm{TS}_{2}$ and compound $\mathbf{6}$, while fixed TR and NADPH concentrations (10 $\mathrm{nM}$ and $40 \mu \mathrm{M}$, respectively) were maintained. After starting the reaction by the addition of NADPH, the absorbance decrease at $340 \mathrm{~nm}$, indicative of NADPH oxidation, was measured. As shown in Figure 4, compound 6 competitively inhibited the binding of $\mathrm{TS}_{2}$ to $\mathrm{TR}$. $\mathrm{K}_{\mathrm{M}}$ and $\mathrm{k}_{\mathrm{cat}}$ of TR used for the $\mathrm{K}_{\mathrm{i}}$ calculation were $23.0 \pm 1.0 \mu \mathrm{M}$ and $11.4 \pm 0.3 \mathrm{~s}^{-1}$ respectively 
[17]. The value of Ki calculated from the Dixon plot analysis was $0.45 \pm 0.11 \mu \mathrm{M}$, about three times lower than that of $\mathrm{Sb}(\mathrm{III})(1.5 \mu \mathrm{M})[13]$.

\subsection{Docking studies}

The crystal structure of TR from L. infantum revealed two crucial cysteine residues (Cys52 and Cys57) in the active site, involved in a concerted nucleophilic attack to the $\mathrm{TS}_{2}$ disulfide bridge to produce the reduced substrate $\mathrm{T}(\mathrm{SH})_{2}$. In order to gain functional and structural insight into the mechanism of inhibition, molecular docking simulations of compound $\mathbf{6}$ to TR were performed using the x-ray structures of the enzyme in both reduced and oxidized states. Figure 5a illustrates the most probable and energetically favourable binding modes of compound $\mathbf{6}$ at the active site of TR in oxidized state (PDB code: 2JK6) and Figure 5b shows the conformation with the lowest energy in the most populated cluster. As shown in TableS1, the most populated cluster contains $32 / 100$ poses and the lowest energy pose in this cluster displays a binding energy of $-7.63 \mathrm{kcal} / \mathrm{mol}$ corresponding to a $\mathrm{Ki}=2.56 \mu \mathrm{M}$. Figure $5 \mathrm{c}$ displays the conformation with the lowest energy in the most populated cluster, resulting from the docking procedure performed using TR in reduced state (PDB code: 4ADW); the clusters and the energies of the poses are reported in TableS2. In this case, the most populated cluster contains $16 / 100$ poses and the lowest energy pose in this cluster displays a binding energy of $-6.66 \mathrm{kcal} / \mathrm{mol}$, corresponding to a $\mathrm{Ki}=13.19 \mu \mathrm{M}$.

As shown in Figure 5, both the docking procedures performed using the TR structures in the oxidized and reduced state gave similar results. Interestingly, in both the procedures the most populated clusters occupy the same portion of the trypanothione cavity volume. Compound $\mathbf{6}$ binds to TR in both oxidized and reduced states at the same hydrophobic pocket close to the two catalytic cysteines lined by the following residues: Ile339, Ile458', His461', E466', E467', S470', F396', L399'. Compound 6 establishes electrostatic interactions with and K61, E467' and S470'. Interestingly, compound $\mathbf{6}$ appears to have a higher affinity for the oxidized form of TR. 


\section{DISCUSSION}

To support the urgent need of safe and effective agents against leishmaniasis. a plethora of bioactive compounds with antileishmanial activity and acting through different mechanisms have been synthetized [27, 28]. Evidence indicates that a number of natural and synthetic chalcones exhibit antileishmanial activity [25, 29-32]. In this study, we evaluated the antileishmanial effect of a small library of synthetic chalcones and we investigated the mechanism of action of selected compounds. Among the 31 tested compounds, 16 (1-16) turned out to inhibit the promastigote form of L.donovani with micromolar potency, and among them, two (6 and 16) showed good potency $\left(\mathrm{IC}_{50} / 72 \mathrm{~h}\right.$ values of 3.0 and $12.5 \mu \mathrm{M}$, respectively), even if lower with respect to the reference drug amphotericin B. Furthermore compounds $\mathbf{6}$ and $\mathbf{1 6}$ maintained a good inhibitory activity when tested on amastigotes of L.donovani ( $\mathrm{IC}_{50}$ values of 14.0 and $4.5 \mu \mathrm{M}$, respectively). Interestingly, these derivatives were characterized by low toxicity when tested on Vero cells and THP-1 cells, being three times less toxic than amphotericin B and thus exhibiting a very favorable SI.

Moreover, compounds $\mathbf{6}$ and $\mathbf{1 6}$ efficiently inhibited the promastigote growth of other leishmanial species, including L.tropica, L.major and L.infantum, being particularly active on L.infantum.

In an effort to assess the mechanism by which $\mathbf{6}$ and $\mathbf{1 6}$ inhibit Leishmania growth, we evaluated their affinity and activity against TR, a pivotal enzyme involved in the parasite detoxification. The enzymes of the trypanothione pathway are not present in mammals, and are often considered among the most promising antileishmanial targets. However, it was previously demonstrated that at least $90 \%$ of TR inactivation needs to be obtained by inhibitor compounds to kill the parasite; therefore, effective TR inhibitors should have submicromolar inhibition activity [12]. Here, we observed that compound 6 showed a submicromolar Ki value vs. TR $(0.45 \pm 0.11 \mu \mathrm{M})$ that is about 6 times lower than the $\mathrm{IC}_{50} / 72 \mathrm{~h}$ value vs. promastigotes and 30 times lower than the $\mathrm{IC}_{50} / 72 \mathrm{~h}$ vs. the amastigotes. This result is in agreement with numerous results present in literature showing that specific and efficient trypanosomatid TR inhibitors have been found to be less active on the parasites growth. This apparent paradox was shown by Krieger and coworkers who produced conditioned TR 
knockout in T. brucei [33], demonstrating that the redox metabolism of the parasite was affected only when TR was titrated down to less than $5 \%$ of normal. Thus, compound 6 is a good TR inhibitor, with a $\mathrm{Ki}$ value remarkably lower than $\mathrm{Sb}$ (III) and azole-based compounds and in the same order of magnitude of RDS 777, a diaryl sulphide derivative [17, 18].

The docking experiments furnished a possible binding mode of compound $\mathbf{6}$ to the catalytic site. Indeed, compound 6 binds to TR in both the oxidized and reduced states to a hydrophobic pocket close to the catalytic site, which was already shown to be part of RDS 777 binding site in the TR trypanothione cleft. Interestingly, F396' and E467' lining the compound 6 binding site have been already identified as important residues to establish interaction with other TR inhibitors [18].

This study has some limitations, including the employment of a small library of chalcones for the screening of antileishmanial activity and the lack of in vivo pharmacokinetic and pharmacodynamic testing of the selected compounds.

\section{CONCLUSIONS}

A small library of 31 chalcone-based analogues were synthetized and tested for their antileishmanial activity. Among tested compounds, $\mathbf{6}$ and $\mathbf{1 6}$ were found to be significantly active in in vitro evaluation against $L$. donovani promastigotes and amastigotes without eliciting cytotoxic effects towards human cells, thus showing optimal performance in terms of potency and selectivity. Furthermore, compounds $\mathbf{6}$ and $\mathbf{1 6}$ inhibited the promastigote growth of other leishmanial species, including L. tropica, L. major and L. infantum. Finally, compounds $\mathbf{6}$ and $\mathbf{1 6}$ interacted with TR and compound $\mathbf{6}$ effectively inhibited TR activity, providing evidence that TR inhibition could represent one of the possible mechanisms of action of this molecule. In conclusion, the effective inhibitory activity against different Leishmania species, the lack of toxicity on mammalian cells and the ability to block a crucial parasite enzyme target, highlight the potential for the chalcone $\mathbf{6}$ to be further optimized and to develop novel drug candidates against leishmaniasis. 


\section{EXPERIMENTAL SECTION}

312

\subsection{Chemistry.}

Starting materials, unless otherwise specified, were used as high grade commercial products. Solvents were of analytical grade. Reaction progress was followed by thin layer chromatography (TLC) on precoated silica gel plates (Merck Silica Gel 60 F254) and then visualized with a UV254 lamplight. Chromatographic separations were performed on Merck silica gel columns by flash method (Kieselgel 40, 0.040-0.063 mm, 240 - 400 mesh). Melting points were determined in open glass capillaries, using a Büchi apparatus and are uncorrected. ${ }^{1} \mathrm{H}$ NMR and ${ }^{13} \mathrm{C}$ NMR spectra were recorded on a Varian Gemini spectrometer $400 \mathrm{MHz}$ and $101 \mathrm{MHz}$, respectively, and chemical shifts $(\delta)$ are reported as parts per million (ppm) values relative to tetramethylsilane (TMS) as internal standard; standard abbreviations indicating spin multiplicities are given as follows: $\mathrm{s}$ (singlet), d (doublet), t (triplet), br (broad), q (quartet) or m (multiplet); coupling constants $(J)$ are reported in Hertz $(\mathrm{Hz})$. Mass spectra were recorded on a Waters ZQ 4000 apparatus operating in electrospray mode (ES). Analyses indicated by the symbols of the elements were within $\pm 0.4 \%$ of the theoretical values. Compounds were named relying on the naming algorithm developed by CambridgeSoft Corporation and used in Chem-BioDraw Ultra 14.0.

\subsection{Williamson Reaction: General Procedure}

A mixture of selected hydroxylated acetophenone (1.0 eq), alkyl halide (1.1-1.5 eq), $\mathrm{K}_{2} \mathrm{CO}_{3}(1.1$ eq) in acetone, was heated for $6-10 \mathrm{~h}$ at $80{ }^{\circ} \mathrm{C}$; reaction progress was monitored by TLC. Upon reaction completion, the mixture was hot filtered and the solvent was evaporated under reduced pressure. The resulting crude product was purified by column chromatography over a silica gel using a mixture of petroleum ether/EtOAc as the eluent to give the desired pure product. 
5.2.1. 1-(2-hydroxy-4-((3-methylbut-2-en-1-yl)oxy)phenyl)ethan-1-one (32) Reaction of 2,4-dihydroxyacetophenone (5.0 mmol, $0.75 \mathrm{~g}$ ) and 3,3-dimethylallyl bromide (5.5 mmol, $0.82 \mathrm{~g}$ ) gave

the crude 32 that was purified by flash chromatography (petroleum ether/EtOAc 9:1), 97\% yield, mp 42-44 ${ }^{\circ} \mathrm{C} .{ }^{1} \mathrm{H}-\mathrm{NMR}\left(\mathrm{CDCl}_{3}\right) \delta 1.88\left(\mathrm{~s}, 3 \mathrm{H}, \mathrm{CH}_{3}\right), 1.91\left(\mathrm{~s}, 3 \mathrm{H}, \mathrm{CH}_{3}\right), 2.55\left(\mathrm{~s}, 3 \mathrm{H}, \mathrm{COCH}_{3}\right), 4.65$ $\left(\mathrm{d}, 2 \mathrm{H}, J=6.6 \mathrm{~Hz}, \mathrm{OCH}_{2}\right), 5.55(\mathrm{t}, 1 \mathrm{H}, J=6.6 \mathrm{~Hz}, \mathrm{CH}), 6.44(\mathrm{~d}, J=1.8 \mathrm{~Hz}, 1 \mathrm{H}, \mathrm{H}-3), 6.54(\mathrm{dd}, J$ $=1.8$ and $8.6 \mathrm{~Hz}, 1 \mathrm{H}, \mathrm{H}-5), 7.78(\mathrm{~d}, J=8.6 \mathrm{~Hz}, 1 \mathrm{H}, \mathrm{H}-6)$.

5.2.2. 1-(2-hydroxy-4-(prop-2-yn-1-yloxy)phenyl)-1-ethanone (33). Reaction of 2,4dihydroxyacetophenone $(5.0 \mathrm{mmol}, 0.75 \mathrm{~g})$ and propargyl bromide solution $80 \mathrm{wt}$. \% in toluene (5.5 mmol, $0.80 \mathrm{~g}$ ) gave the crude final product $\mathbf{3 3}$ that was purified by flash chromatography (petroleum ether/EtOAc 7:3), 93\% yield, mp 64-66 ${ }^{\circ} \mathrm{C} .{ }^{1} \mathrm{H}-\mathrm{NMR}\left(\mathrm{CDCl}_{3}\right) \delta 2.55\left(\mathrm{~s}, 3 \mathrm{H}, \mathrm{CH}_{3}\right), 2.60$ $(\mathrm{s}, 1 \mathrm{H}, \mathrm{CH}), 4.72\left(\mathrm{~s}, 2 \mathrm{H}, \mathrm{OCH}_{2}\right), 6.44(\mathrm{~d}, J=1.8 \mathrm{~Hz}, 1 \mathrm{H}, \mathrm{H}-3), 6.55(\mathrm{dd}, J=1.8$ and $8.6 \mathrm{~Hz}, 1 \mathrm{H}, \mathrm{H}-$ 5), $7.70(\mathrm{~d}, J=8.6 \mathrm{~Hz}, 1 \mathrm{H}, \mathrm{H}-6)$.

5.2.3. 1-(2-methoxy-4-((3-methylbut-2-en-1-yl)oxy)phenyl)ethan-1-one (34). Reaction of 32 (4.2 g, $20.1 \mathrm{mmol})$ with methyl iodide $(4.18 \mathrm{~g}, 30.25 \mathrm{mmol})$ gave the crude final product 34 that was purified by flash chromatography (petroleum ether/EtOAc 9.75:0.25), 93\% yield, mp 74-76 ${ }^{\circ} \mathrm{C} .{ }^{1} \mathrm{H}-$ NMR $\left(\mathrm{CDCl}_{3}\right) \delta 1.77\left(\mathrm{~s}, 3 \mathrm{H}, \mathrm{CH}_{3}\right), 1.81\left(\mathrm{~s}, 3 \mathrm{H}, \mathrm{CH}_{3}\right), 2.57\left(\mathrm{~s}, 3 \mathrm{H}, \mathrm{COCH}_{3}\right), 3.00\left(\mathrm{~s}, 3 \mathrm{H}, \mathrm{OCH}_{3}\right)$, $4.58\left(\mathrm{~d}, 2 \mathrm{H}, J=6.6 \mathrm{~Hz}, \mathrm{OCH}_{2}\right), 5.48(\mathrm{t}, 1 \mathrm{H}, J=6.6 \mathrm{~Hz}, \mathrm{CH}), 6.42(\mathrm{~d}, J=1.8 \mathrm{~Hz}, 1 \mathrm{H}, \mathrm{H}-3), 6.53$ (dd, $J=1.8$ and $8.6 \mathrm{~Hz}, 1 \mathrm{H}, \mathrm{H}-5), 7.83$ (d, $J=8.6 \mathrm{~Hz}, 1 \mathrm{H}, \mathrm{H}-6)$.

5.2.4. 1-(2,4-bis((3-methylbut-2-en-1-yl)oxy)phenyl)ethan-1-one (35). Reaction of 32 (4.2 g, 20.1 mmol) with 3,3-dimethylallyl bromide $(4.41 \mathrm{~g}, 30.25 \mathrm{mmol})$ gave the crude final product 35 that was purified by flash chromatography (petroleum ether/EtOAc 9.75:0.25) as transparent oil, $56 \%$ yield. ${ }^{1} \mathrm{H}$ NMR $\left(\mathrm{CDCl}_{3}\right) \delta 1.75\left(\mathrm{~s}, 3 \mathrm{H}, \mathrm{CH}_{3}\right), 1.80\left(\mathrm{~s}, 3 \mathrm{H}, \mathrm{CH}_{3}\right), 1.84\left(\mathrm{~s}, 3 \mathrm{H}, \mathrm{CH}_{3}\right), 1.88(\mathrm{~s}, 3 \mathrm{H}$, $\left.\mathrm{CH}_{3}\right), 2.55\left(\mathrm{~s}, 3 \mathrm{H}, \mathrm{COCH}_{3}\right), 4.50\left(\mathrm{~d}, 2 \mathrm{H}, J=6.6 \mathrm{~Hz}, \mathrm{OCH}_{2}\right), 4.57\left(\mathrm{~d}, 2 \mathrm{H}, J=6.6 \mathrm{~Hz}, \mathrm{OCH}_{2}\right), 5.44$ 
$(\mathrm{t}, 1 \mathrm{H}, J=6.6 \mathrm{~Hz}, \mathrm{CH}), 5.60(\mathrm{t}, 1 \mathrm{H}, J=6.6 \mathrm{~Hz}, \mathrm{CH}), 6.45(\mathrm{~d}, J=1.8 \mathrm{~Hz}, 1 \mathrm{H}, \mathrm{H}-3), 6.58(\mathrm{dd}, J=$ 1.8 and $8.6 \mathrm{~Hz}, 1 \mathrm{H}, \mathrm{H}-5), 7.81$ (d, $J=8.6 \mathrm{~Hz}, 1 \mathrm{H}, \mathrm{H}-6)$.

5.2.5. 1-(2-methoxy-4-(prop-2-yn-1-yloxy)phenyl)ethan-1-one (36). Reaction of 33 (3.16 g, 17.7 mmol) with methyl iodide $(3.75 \mathrm{~g}, 26.55 \mathrm{mmol}$ ) gave the crude final product 36 that was purified by flash chromatography (petroleum ether/EtOAc 9.5:0.5), 92\%, yield, mp 93-95 ${ }^{\circ} \mathrm{C} .{ }^{1} \mathrm{H}$ NMR $\left(\mathrm{CDCl}_{3}\right) \delta 2.59-2.61\left(\mathrm{~m}, 4 \mathrm{H}, \mathrm{COCH}_{3}\right.$ and $\left.\mathrm{CH}\right), 3.95\left(\mathrm{~s}, 3 \mathrm{H}, \mathrm{OCH}_{3}\right), 4.78\left(\mathrm{~s}, 2 \mathrm{H}, \mathrm{OCH}_{2}\right), 6.57(\mathrm{~d}, J=$ $1.8 \mathrm{~Hz}, 1 \mathrm{H}, \mathrm{H}-3), 6.59$ (dd, $J=1.8$ and $8.6 \mathrm{~Hz}, 1 \mathrm{H}, \mathrm{H}-5), 7.82$ (d, $J=8.6 \mathrm{~Hz}, 1 \mathrm{H}, \mathrm{H}-6)$.

5.2.6. 1-(2,4-bis(prop-2-yn-1-yloxy)phenyl)ethan-1-one (37). Reaction of 33 (3.16 g, $17.7 \mathrm{mmol})$ with propargyl bromide solution 80 wt. \% in toluene $(4.97 \mathrm{~g}, 26.55 \mathrm{mmol})$ gave the crude final product 37 that was purified by flash chromatography (petroleum ether/EtOAc 9.5/0.5), $75 \%$ yield, mp 101-103 ${ }^{\circ} \mathrm{C} .{ }^{1} \mathrm{H}$ NMR $\left(\mathrm{CDCl}_{3}\right) \delta$ 2.59-2.61 (m, 5H, $\mathrm{COCH}_{3}$ and $\left.\mathrm{CH}_{2}\right), 4.78\left(\mathrm{~s}, 2 \mathrm{H}, \mathrm{OCH}_{2}\right), 4.81$ $\left(\mathrm{s}, 2 \mathrm{H}, \mathrm{OCH}_{2}\right), 6.57(\mathrm{~d}, J=1.8 \mathrm{~Hz}, 1 \mathrm{H}, \mathrm{H}-3), 6.57(\mathrm{dd}, J=1.8$ and $8.6 \mathrm{~Hz}, 1 \mathrm{H}, \mathrm{H}-5), 7.80(\mathrm{~d}, J=$ $8.6 \mathrm{~Hz}, 1 \mathrm{H}, \mathrm{H}-6)$.

\subsection{Claisen-Schmidt reaction: General Procedure}

To an ethanol solution of acetophenone (32-37, 1.0 eq) and the selected benzaldehyde (1.1 eq), a $\mathrm{KOH}$ aqueous solution (50\% p/v, 6 eq) was added dropwise. The reaction mixture was stirred at room temperature overnight, then diluted with water and acidified with $6 \mathrm{~N} \mathrm{HCl}$. The separated solid was collected by vacuum filtration and was purified by flash chromatography using petroleum ether/EtOAc as eluent. The final products were crystallized from suitable solvent.

5.3.1. (E)-1-(2-hydroxy-4-((3-methylbut-2-en-1-yl)oxy)phenyl)-3-(pyridin-4-yl)prop-2-en-1-one (1). Starting from $32(0.22 \mathrm{~g}, 1.0 \mathrm{mmol})$ and 4-pyridinecarboxaldehyde $(0.19 \mathrm{~g}, 1.1 \mathrm{mmol})$ the crude final product 1 was obtained and was purified by crystallization from $\mathrm{EtOH}$ to obtain a red-orange solid (0.14 g), 45\% yield, mp 102-103 ${ }^{\circ} \mathrm{C} .{ }^{1} \mathrm{H} \mathrm{NMR}\left(\mathrm{CDCl}_{3}\right) \delta 1.77\left(\mathrm{~s}, 3 \mathrm{H}, \mathrm{CH}_{3}\right), 1.82\left(\mathrm{~s}, 3 \mathrm{H}, \mathrm{CH}_{3}\right)$, $4.59\left(\mathrm{~d}, J=6.4 \mathrm{~Hz}, 2 \mathrm{H}, \mathrm{OCH}_{2}\right), 5.49-5.53(\mathrm{~m}, 1 \mathrm{H}, \mathrm{CH}=\mathrm{C}), 6.50(\mathrm{~d}, J=1.8 \mathrm{~Hz}, 1 \mathrm{H}, \mathrm{H}-3), 6.52$ (dd, 
$J=1.8$ and $J=8.4 \mathrm{~Hz}, 1 \mathrm{H}, \mathrm{H}-5), 7.49\left(\mathrm{~d}, J=4.4 \mathrm{~Hz}, 2 \mathrm{H}, \mathrm{H}-2^{\prime}\right.$ ' and H-6'), $7.71(\mathrm{~d}, J=15.6 \mathrm{~Hz}, 1 \mathrm{H}$, $=\mathrm{CH}), 7.73(\mathrm{~d}, J=15.6 \mathrm{~Hz}, 1 \mathrm{H}, \mathrm{CH}=), 7.81(\mathrm{~d}, J=8.8 \mathrm{~Hz}, 1 \mathrm{H}, \mathrm{H}-6), 8.70(\mathrm{~d}, J=4.4 \mathrm{~Hz}, 2 \mathrm{H}, \mathrm{H}-3$ ' and $\mathrm{H}-5$ ' $) .{ }^{13} \mathrm{C} \mathrm{NMR}\left(\mathrm{CDCl}_{3}\right) \delta 18.2,25.7,65.3,101.7,108.6,113.8,118.5,122.0,124.7,131.2$, 138.5, 141.0, 142.0, 148.8, 149.5, 166.0, 166.9, 192.1. ESI-MS $(\mathrm{m} / \mathrm{z}): 310(\mathrm{M}+\mathrm{H})$; Anal. $\mathrm{C}_{19} \mathrm{H}_{19} \mathrm{NO}_{3}(\mathrm{C}, \mathrm{H}, \mathrm{N})$.

5.3.2. (E)-1-(2-hydroxy-4-((3-methylbut-2-en-1-yl)oxy)phenyl)-3-(pyridin-3-yl)prop-2-en-1-one (2).

Starting from $32(0.22 \mathrm{~g}, 1.0 \mathrm{mmol})$ and 3-pyridinecarboxaldehyde $(0.19 \mathrm{~g}, 1.1 \mathrm{mmol})$ gave the crude final product 2 that was purified by crystallization from EtOH to obtain a orange solid $(0.21$ g), 67\% yield, mp 108-109 ${ }^{\circ} \mathrm{C} .{ }^{1} \mathrm{H}$ NMR $\left(\mathrm{CDCl}_{3}\right) \delta 1.77\left(\mathrm{~s}, 3 \mathrm{H}, \mathrm{CH}_{3}\right), 1.82\left(\mathrm{~s}, 3 \mathrm{H}, \mathrm{CH}_{3}\right), 4.59(\mathrm{~d}, J$ $\left.=6.4 \mathrm{~Hz}, 2 \mathrm{H}, \mathrm{OCH}_{2}\right), 5.49-5.53(\mathrm{~m}, 1 \mathrm{H}, \mathrm{CH}=\mathrm{C}), 6.51(\mathrm{~d}, J=2.0 \mathrm{~Hz} 1 \mathrm{H}, \mathrm{H}-3), 6.53(\mathrm{dd}, J=8.8$ and $2.0 \mathrm{~Hz}, 1 \mathrm{H}, \mathrm{H}-5), 7.32-7.36(\mathrm{~m}, 1 \mathrm{H}, \mathrm{H}-5$ ') $, 7.62(\mathrm{~d}, J=15.6 \mathrm{~Hz}, 1 \mathrm{H},=\mathrm{CH}), 7.82(\mathrm{~d}, J=16.0 \mathrm{~Hz}, 1 \mathrm{H}$, $\mathrm{CH}=), 7.84(\mathrm{~d}, J=8.8 \mathrm{~Hz}, 1 \mathrm{H}, \mathrm{H}-6$ ') 7.79 (d, $J=7.6 \mathrm{~Hz}, 1 \mathrm{H}, \mathrm{H}-6), 8.61$ (d, $\left.J=4.8 \mathrm{~Hz}, 1 \mathrm{H}, \mathrm{H}-4^{\prime}\right)$, $8.94\left(\mathrm{~s}, 1 \mathrm{H}, \mathrm{H}-2\right.$ '). ${ }^{13} \mathrm{C} \mathrm{NMR}\left(\mathrm{CDCl}_{3}\right) \delta 18.66,25.6,65.2,102.7,107.6,113.8,119.2,123.5,125.7$, 131.2, 138.4, 144.0, 144.1, 149.8, 149.5, 166.0, 166.7, 192.8. ESI-MS (m/z): $310(\mathrm{M}+\mathrm{H})$; Anal. $\mathrm{C}_{19} \mathrm{H}_{19} \mathrm{NO}_{3}(\mathrm{C}, \mathrm{H}, \mathrm{N})$.

5.3.3. (E)-1-(2-methoxy-4-((3-methylbut-2-en-1-yl)oxy)phenyl)-3-(pyridin-4-yl)prop-2-en-1-one (3). Starting from $34(0.23 \mathrm{~g}, 1.0 \mathrm{mmol})$ and 4-pyridinecarboxaldehyde $(0.19 \mathrm{~g}, 1.1 \mathrm{mmol})$ gave the crude final product 3 that was purified by flash chromatography (DCM/MeOH 9.75:0.25) and then crystallized from AcOEt/n-hexane to obtain a solid(0.09 g), 30\% yield, mp 102-103 ${ }^{\circ} \mathrm{C} .{ }^{1} \mathrm{H}$ NMR $\left(\mathrm{CDCl}_{3}\right) \delta 1.79\left(\mathrm{~s}, 3 \mathrm{H}, \mathrm{CH}_{3}\right), 1.82\left(\mathrm{~s}, 3 \mathrm{H}, \mathrm{CH}_{3}\right), 3.96\left(\mathrm{~s}, 3 \mathrm{H}, \mathrm{OCH}_{3}\right), 4.51(\mathrm{~d}, J=6.4 \mathrm{~Hz}, 2 \mathrm{H}$, $\left.\mathrm{OCH}_{2}\right), 5.44-5.51(\mathrm{~m}, 1 \mathrm{H}, \mathrm{CH}=\mathrm{C}), 6.30(\mathrm{~d}, J=1.8 \mathrm{~Hz}, 1 \mathrm{H}, \mathrm{H}-3), 6.42(\mathrm{dd}, J=1.8$ and $8.4 \mathrm{~Hz}, 1 \mathrm{H}$, H-5), 7.49 (d, $J=4.4 \mathrm{~Hz}, 2 \mathrm{H}, \mathrm{H}-2^{\prime}$ and H-6'), $7.70(\mathrm{~d}, J=15.6 \mathrm{~Hz}, 1 \mathrm{H},=\mathrm{CH}), 7.72(\mathrm{~d}, J=15.6 \mathrm{~Hz}$, $1 \mathrm{H}, \mathrm{CH}=), 7.80(\mathrm{~d}, J=8.8 \mathrm{~Hz}, 1 \mathrm{H}, \mathrm{H}-6), 8.65(\mathrm{~d}, J=4.4 \mathrm{~Hz}, 2 \mathrm{H}, \mathrm{H}-3$ ' and $\mathrm{H}-5$ ' $) .{ }^{13} \mathrm{C}$ NMR $\left(\mathrm{CDCl}_{3}\right) \delta 18.5,24.5,55.2,64.3,101.9,107.6,113.8,119.1,123.0,125.7,131.2,138.5,144.1$, 144.6, 148.8, 149.3, 162.1, 166.5, 192.5. ESI-MS (m/z): $324(\mathrm{M}+\mathrm{H})$; Anal. $\mathrm{C}_{20} \mathrm{H}_{21} \mathrm{NO}_{3}(\mathrm{C}, \mathrm{H}, \mathrm{N})$. 
5.3.4. (E)-1-(2-methoxy-4-((3-methylbut-2-en-1-yl)oxy)phenyl)-3-(pyridin-3-yl)prop-2-en-1-one (4).

Starting from $34(0.23 \mathrm{~g}, 1.0 \mathrm{mmol})$ and 3-pyridinecarboxaldehyde $(0.19 \mathrm{~g}, 1.1 \mathrm{mmol})$ gave the crude final product 4 that was purified by flash chromatography (DCM/MeOH 9.75:0.25) and then crystallized from AcOEt/n-hexane to obtain an orange solid $(0.14 \mathrm{~g}), 45 \%$ yield, mp $98-100{ }^{\circ} \mathrm{C} .{ }^{1} \mathrm{H}$ NMR $\left(\mathrm{CDCl}_{3}\right) \delta 1.78\left(\mathrm{~s}, 3 \mathrm{H}, \mathrm{CH}_{3}\right), 1.83\left(\mathrm{~s}, 3 \mathrm{H}, \mathrm{CH}_{3}\right), 3.93\left(\mathrm{~s}, 3 \mathrm{H}, \mathrm{OCH}_{3}\right), 4.78(\mathrm{~d}, J=4 \mathrm{~Hz}, 2 \mathrm{H}$, $\left.\mathrm{OCH}_{2}\right)$ 5.49-5.53 (m, 1H, CH=C), $6.61(\mathrm{~s}, 1 \mathrm{H}, \mathrm{H}-3), 6.66(\mathrm{~d}, J=8.8 \mathrm{~Hz}, 1 \mathrm{H}, \mathrm{H}-5)$ 7.34-7.37 (m, $\left.1 \mathrm{H}, \mathrm{H}-5^{\prime}\right), 7.56(\mathrm{~d}, J=15.6 \mathrm{~Hz}, 1 \mathrm{H},=\mathrm{CH}), 7.62(\mathrm{~d}, J=16 \mathrm{~Hz}, 1 \mathrm{H}, \mathrm{CH}=), 7.80(\mathrm{~d}, J=8.8 \mathrm{~Hz}, 1 \mathrm{H}$, H-6'), 7.89 (d, $J=7.6 \mathrm{~Hz}, 1 \mathrm{H}, \mathrm{H}-6), 8.60$ (d, $J=4.8 \mathrm{~Hz}, 1 \mathrm{H}, \mathrm{H}-4$ '), 8.84 (s, 1H, H-2'). ${ }^{13} \mathrm{C}$ NMR $\left(\mathrm{CDCl}_{3}\right) \delta 18.4,24.7,55.8,64.9,101.5,107.6,119.3,123.5,127.1,129.7,131.3,132.7,138.4$ 141.1, 148.0, 148.6, 149.3, 163.3, 168.3, 192.2. ESI-MS (m/z): $324(\mathrm{M}+\mathrm{H}) ;$ Anal. $\mathrm{C}_{20} \mathrm{H}_{21} \mathrm{NO}_{3}(\mathrm{C}$, $\mathrm{H}, \mathrm{N})$.

5.3.5. (E)-3-(4-bromophenyl)-1-(2-methoxy-4-((3-methylbut-2-en-1-yl)oxy)phenyl)prop-2-en-1-one (5). Starting from $34(0.23 \mathrm{~g}, 1.0 \mathrm{mmol})$ and 4-bromobenzaldehyde $(0.20 \mathrm{~g}, 1.1 \mathrm{mmol})$ gave the crude final product 5 that was purified by flash chromatography (petroleum ether/AcOEt 4:1) and then crystallized from AcOEt/n-hexane to obtain a yellow solid $(0.32 \mathrm{~g}), 81 \%$ yield, mp $96-98{ }^{\circ} \mathrm{C}$. ${ }^{1} \mathrm{H} \mathrm{NMR}\left(\mathrm{CDCl}_{3}\right) \delta 1.78\left(\mathrm{~s}, 3 \mathrm{H}, \mathrm{CH}_{3}\right), 1.83\left(\mathrm{~s}, 3 \mathrm{H}, \mathrm{CH}_{3}\right), 3.91\left(\mathrm{~s}, 3 \mathrm{H}, \mathrm{OCH}_{3}\right), 4.59(\mathrm{~d}, J=6.4 \mathrm{~Hz}$, 2H, $\left.\mathrm{OCH}_{2}\right), 5.49-5.53(\mathrm{~m}, 1 \mathrm{H}, \mathrm{CH}=\mathrm{C}), 6.64(\mathrm{~d}, J=2.0 \mathrm{~Hz}, 1 \mathrm{H}, \mathrm{H}-3), 6.72(\mathrm{dd}, J=2.0$ and $8.8 \mathrm{~Hz}$, 1H, H-5), $7.62(\mathrm{~d}, J=15.6 \mathrm{~Hz}, 1 \mathrm{H},=\mathrm{CH}), 7.66(\mathrm{~d}, J=15.8 \mathrm{~Hz}, 1 \mathrm{H}, \mathrm{CH}=), 7.76(\mathrm{~d}, J=8.8 \mathrm{~Hz}, 2 \mathrm{H}$, H-2' and H-6'), 7.80 (d, $J=8.4 \mathrm{~Hz}, 1 \mathrm{H}, \mathrm{H}-6), 8.24$ (d, $J=8.8 \mathrm{~Hz}, 2 \mathrm{H}, \mathrm{H}-3$ ' and H-5'). ${ }^{13} \mathrm{C}$ NMR $\left(\mathrm{CDCl}_{3}\right) \delta 18.3,24.9,54.2,65.1,100.3,106.6,118.7,119.9,123.4,128.2,128.4,131.8,133.5$, 138.9, 145.4, 162.4, 168.8, 191.2. ESI-MS (m/z): $402(\mathrm{M}+\mathrm{H})$; Anal. $\mathrm{C}_{21} \mathrm{H}_{21} \mathrm{BrO}_{3}(\mathrm{C}, \mathrm{H}$,$) .$

5.3.6. (E)-1-(2-methoxy-4-((3-methylbut-2-en-1-yl)oxy)phenyl)-3-(4-nitrophenyl)prop-2-en-1-one (6). Starting from $34(0.23 \mathrm{~g}, 1.0 \mathrm{mmol})$ and 4-nitrobenzaldehyde (0.17 g, $1.1 \mathrm{mmol})$ gave the crude final product 6 that was purified by crystallization from EtOH to obtain a yellow solid (0.28 $\mathrm{g})$, 77\% yield, mp $147-147{ }^{\circ} \mathrm{C} .{ }^{1} \mathrm{H}$ NMR $\left(\mathrm{CDCl}_{3}\right) \delta 1.77\left(\mathrm{~s}, 3 \mathrm{H}, \mathrm{CH}_{3}\right), 1.82\left(\mathrm{~s}, 3 \mathrm{H}, \mathrm{CH}_{3}\right), 3.93(\mathrm{~s}, 3 \mathrm{H}$, 
$\left.431 \mathrm{OCH}_{3}\right), 4.57\left(\mathrm{~d}, J=6.4 \mathrm{~Hz}, 2 \mathrm{H}, \mathrm{OCH}_{2}\right), 5.49-5.53(\mathrm{~m}, 1 \mathrm{H}, \mathrm{CH}=\mathrm{C}), 6.52(\mathrm{~d}, J=1.6 \mathrm{~Hz}, 1 \mathrm{H}, \mathrm{H}-3)$,

432

433

434

435

436

437

438

439

440

441

442

443

444

445

446

447

448

449

450

451

452

453

454

$6.58(\mathrm{dd}, J=1.6$ and $8.0 \mathrm{~Hz}, 1 \mathrm{H}, \mathrm{H}-5), 7.68(\mathrm{~d}, J=16.0 \mathrm{~Hz}, 1 \mathrm{H},=\mathrm{CH}), 7.59(\mathrm{~d}, J=16.0 \mathrm{~Hz}, 1 \mathrm{H}$, $\mathrm{CH}=), 7.72\left(\mathrm{~d}, J=8.4 \mathrm{~Hz}, 1 \mathrm{H}, \mathrm{H}-2^{\prime}\right.$ and H-6'), $7.81(\mathrm{~d}, J=8.4 \mathrm{~Hz}, 1 \mathrm{H}, \mathrm{H}-6), 8.26$ (d, $J=8.4 \mathrm{~Hz}$, 1H, $\mathrm{H}-3$ ' and $\mathrm{H}-5$ ' $) .{ }^{13} \mathrm{C} \mathrm{NMR}\left(\mathrm{CDCl}_{3}\right) \delta 18.2,25.8,55.7,65.1,105.8,118.9,121.3,124.1,128.6$, 131.0, 133.2, 138.2, 141.9, 160.7, 164.2, 183.2. ESI-MS $(m / z): 368(\mathrm{M}+\mathrm{H})$; Anal. $\mathrm{C}_{21} \mathrm{H}_{21} \mathrm{NO}_{5}(\mathrm{C}$, $\mathrm{H}, \mathrm{N}$ ).

\subsection{7. (E)-1-(2-methoxy-4-((3-methylbut-2-en-1-yl)oxy)phenyl)-3-phenylprop-2-en-1-one}

Starting from $34(0.23 \mathrm{~g}, 1.0 \mathrm{mmol})$ and benzaldehyde $(0.11 \mathrm{~g}, 1.1 \mathrm{mmol})$ gave the crude final product 7 that was purified by flash chromatography (petroleum ether/AcOEt 9.5:0.5) to obtain a yellow solid $(0.14 \mathrm{~g}), 42 \%$ yield, mp $147-149{ }^{\circ} \mathrm{C} .{ }^{1} \mathrm{H} \mathrm{NMR}\left(\mathrm{CDCl}_{3}\right) \delta 1.78\left(\mathrm{~s}, 3 \mathrm{H}, \mathrm{CH}_{3}\right), 1.82(\mathrm{~s}$, $\left.3 \mathrm{H}, \mathrm{CH}_{3}\right), 3.90\left(\mathrm{~s}, 3 \mathrm{H}, \mathrm{OCH}_{3}\right), 4.58\left(\mathrm{~d}, J=6.4 \mathrm{~Hz}, 2 \mathrm{H}, \mathrm{OCH}_{2}\right), 5.49-5.53(\mathrm{~m}, 1 \mathrm{H}, \mathrm{CH}=\mathrm{C}), 6.53(\mathrm{~d}, J$ $=1.6 \mathrm{~Hz}, 1 \mathrm{H}, \mathrm{H}-3), 6.57$ (dd, $J=1.6$ and $8.0 \mathrm{~Hz}, 1 \mathrm{H}, \mathrm{H}-5), 7.30-7.43$ (m, 3H, H-3'-H-5'), 7.53 (d, $J$ $=15.6 \mathrm{~Hz}, 1 \mathrm{H}, \mathrm{CH}=), 7.61-7.67\left(\mathrm{~m}, 2 \mathrm{H}, \mathrm{H}-2^{\prime}\right.$ and H-6'), $7.68(\mathrm{~d}, J=15.6 \mathrm{~Hz}, 1 \mathrm{H}, \mathrm{CH}=), 7.77$ (d, $J$ $=8.4 \mathrm{~Hz}, 1 \mathrm{H}, \mathrm{H}-6) .{ }^{13} \mathrm{C} \mathrm{NMR}\left(\mathrm{CDCl}_{3}\right) \delta 18.2,25.8,55.7,65.0,99.3,105.8,118.9,122.0,127.2$, 128.2, 128.8, 129.9, 132.8, 135.5, 141.9, 160.4, 163.5, 190.6. ESI-MS (m/z): $323(\mathrm{M}+\mathrm{H})$; Anal. $\mathrm{C}_{20} \mathrm{H}_{22} \mathrm{O}_{3}(\mathrm{C}, \mathrm{H})$.

5.3.8. (E)-1-(2-methoxy-4-((3-methylbut-2-en-1-yl)oxy)phenyl)-3-(3,4,5-trimethoxyphenyl)prop-2en-1-one (8). Starting from $34(0.23 \mathrm{~g}, 1.0 \mathrm{mmol})$ and 3,4,5-trimethoxybenzaldehyde $(0.21 \mathrm{~g}, 1.1$ mmol) gave the crude final product $\mathbf{8}$ that was purified by crystallization from EtOH to obtain a yellow solid $(0.29 \mathrm{~g}), 71 \%$ yield, mp 62-64 ${ }^{\circ} \mathrm{C} .{ }^{1} \mathrm{H} \mathrm{NMR}\left(\mathrm{CDCl}_{3}\right) \delta 1.78\left(\mathrm{~s}, 3 \mathrm{H}, \mathrm{CH}_{3}\right), 1.82(\mathrm{~s}, 3 \mathrm{H}$, $\left.\mathrm{CH}_{3}\right), 3.90\left(\mathrm{~s}, 3 \mathrm{H}, \mathrm{OCH}_{3}\right), 3.89\left(\mathrm{~s}, 9 \mathrm{H}, \mathrm{OCH}_{3}\right), 4.57\left(\mathrm{~d}, J=6.4 \mathrm{~Hz}, 2 \mathrm{H}, \mathrm{OCH}_{2}\right), 5.49-5.53(\mathrm{~m}, 1 \mathrm{H}$, $\mathrm{CH}), 6.52(\mathrm{~d}, J=1.6 \mathrm{~Hz}, 1 \mathrm{H}, \mathrm{H}-3), 6.57(\mathrm{dd}, J=1.6$ and $8.0 \mathrm{~Hz}, 1 \mathrm{H}, \mathrm{H}-5), 6.81(\mathrm{~s}, 2 \mathrm{H}, \mathrm{H}-2$ ' and H6'), $7.34(\mathrm{~d}, J=15.6 \mathrm{~Hz}, 1 \mathrm{H}, \mathrm{CH}=), 7.54$ (d, $J=15.6 \mathrm{~Hz}, 1 \mathrm{H}, \mathrm{CH}=), 7.70$ (d, $J=8.4 \mathrm{~Hz}, 1 \mathrm{H}, \mathrm{H}-6)$. ${ }^{13} \mathrm{C} \mathrm{NMR}\left(\mathrm{CDCl}_{3}\right) \delta 18.7,25.7,55.6,56.7,56.9,60.5,63.8,99.9,103.8,107.4,118.5,118.9,123.0$, 
126.6, 131.3, 132.8, 138.5, 138.7, 145.9, 153.1, 153.8, 162.2, 168.8, 190.6. ESI-MS (m/z): $413(\mathrm{M}+$ $\mathrm{H})$; Anal. $\mathrm{C}_{24} \mathrm{H}_{28} \mathrm{O}_{6}(\mathrm{C}, \mathrm{H})$.

5.3.9. (E)-1-(2-hydroxy-4-(prop-2-yn-1-yloxy)phenyl)-3-(pyridin-3-yl)prop-2-en-1-one (9). Starting from $33(0.19 \mathrm{~g}, 1.0 \mathrm{mmol})$ and 3-pyridinecarboxaldehyde $(0.19 \mathrm{~g}, 1.1 \mathrm{mmol})$ gave the crude final product 9 that was purified by crystallization from EtOH to obtain an orange solid $(0.22 \mathrm{~g}), 79 \%$ yield, mp 122-124 ${ }^{\circ} \mathrm{C} .{ }^{1} \mathrm{H}$ NMR $\left(\mathrm{CDCl}_{3}\right) \delta 2.58(\mathrm{~s}, 1 \mathrm{H}, \mathrm{C} \equiv \mathrm{CH}), 4.77\left(\mathrm{~d}, J=1.6 \mathrm{~Hz}, 2 \mathrm{H}, \mathrm{OCH}_{2}\right)$, $6.61(\mathrm{~d}, J=1.8 \mathrm{~Hz}, 1 \mathrm{H}, \mathrm{H}-3), 6.66(\mathrm{dd}, J=8.8$ and $1.8 \mathrm{~Hz}, 1 \mathrm{H}, \mathrm{H}-5), 7.34-7.37$ (m, 1H, H-5'), 7.56 $(\mathrm{d}, J=15.6 \mathrm{~Hz}, 1 \mathrm{H},=\mathrm{CH}), 7.64(\mathrm{~d}, J=15.6 \mathrm{~Hz}, 1 \mathrm{H}, \mathrm{CH}=), 7.81(\mathrm{~d}, J=8.4 \mathrm{~Hz}, 1 \mathrm{H}, \mathrm{H}-6$ ') 7.89 (d, $J=4.8 \mathrm{~Hz}, 1 \mathrm{H}, \mathrm{H}-6), 8.60$ (d, $J=4.8 \mathrm{~Hz}, 1 \mathrm{H}, \mathrm{H}-4$ '), 8.84 (s, 1H, H-2'). ${ }^{13} \mathrm{C} \mathrm{NMR}\left(\mathrm{CDCl}_{3}\right) \delta 55.8$, 76.3, 76.8, 101.6, 106.7, 127.6, 129.6, 131.3, 132.6, 133.8, 134.9, 145.6, 147.9, 149.8, 160.3, 162.4, 190.1. ESI-MS (m/z): $280(\mathrm{M}+\mathrm{H})$; Anal. $\mathrm{C}_{17} \mathrm{H}_{13} \mathrm{NO}_{3}(\mathrm{C}, \mathrm{H}, \mathrm{N})$.

5.3.10. (E)-1-(2-methoxy-4-(prop-2-yn-1-yloxy)phenyl)-3-(pyridin-4-yl)prop-2-en-1-one (10). Starting from $36(0.20 \mathrm{~g}, 1.0 \mathrm{mmol})$ and 4-pyridinecarboxaldehyde $(0.19 \mathrm{~g}, 1.1 \mathrm{mmol})$ gave the crude final product 10 that was purified by flash chromatography (DCM/MeOH 9.75:0.25) and then crystallized from ethanol to obtain a brown solid $(0.11 \mathrm{~g}), 36 \%$ yield, mp $98-100{ }^{\circ} \mathrm{C} .{ }^{1} \mathrm{H}$ NMR $\left(\mathrm{CDCl}_{3}\right): \delta 2.56(\mathrm{~s}, 1 \mathrm{H}, \mathrm{C} \equiv \mathrm{CH}), 3.91\left(\mathrm{~s}, 3 \mathrm{H}, \mathrm{OCH}_{3}\right), 4.75\left(\mathrm{~d}, J=2.0 \mathrm{~Hz}, 2 \mathrm{H}, \mathrm{OCH}_{2}\right), 6.58(\mathrm{~d}, J=$ $1.6 \mathrm{~Hz}, 1 \mathrm{H}, \mathrm{H}-3), 6.64(\mathrm{dd}, J=2$ and $8.4 \mathrm{~Hz}, 1 \mathrm{H}, \mathrm{H}-5), 7.40$ (d, $J=5.6 \mathrm{~Hz}, 2 \mathrm{H}, \mathrm{H}-2$ ' and H-6'), $7.54(\mathrm{~d}, J=16.0 \mathrm{~Hz}, 1 \mathrm{H},=\mathrm{CH}), 7.65(\mathrm{~d}, J=16.0 \mathrm{~Hz}, 1 \mathrm{H}, \mathrm{CH}=), 7.79(\mathrm{~d}, J=8.4 \mathrm{~Hz}, 1 \mathrm{H}, \mathrm{H}-6), 8.63$ $\left(\mathrm{d}, J=5.6 \mathrm{~Hz}, 2 \mathrm{H}, \mathrm{H}-3^{\prime}\right.$ and $\left.\mathrm{H}-5^{\prime}\right) .{ }^{13} \mathrm{C} \mathrm{NMR}\left(\mathrm{CDCl}_{3}\right) \delta 55.7,56.6,76.3,77.7,102.5,107.7,113.8$, $118.2,123.5,125.7,130.2,138.7,144.5,146.3,149.9,150.5,166.0,166.7,192.6$. ESI-MS $(\mathrm{m} / z)$ : $294(\mathrm{M}+\mathrm{H}) ;$ Anal. $\mathrm{C}_{18} \mathrm{H}_{15} \mathrm{NO}_{3}(\mathrm{C}, \mathrm{H}, \mathrm{N})$.

Starting from $36(0.20 \mathrm{~g}, 1.0 \mathrm{mmol})$ and 3-pyridinecarboxaldehyde $(0.19 \mathrm{~g}, 1.1 \mathrm{mmol})$ gave the crude final product 11 that was purified by flash chromatography (DCM/MeOH 9.75:0.25) and then 
479

480

481

482

483

484

485

486

487

488

489

490

491

492

493

494

495

496

497

498

499

500

501

502

crystallized from ethanol to obtain a yellow solid $(0.21 \mathrm{~g}), 72 \%$ yield, mp $120-122{ }^{\circ} \mathrm{C} .{ }^{1} \mathrm{H}$ NMR $\left(\mathrm{CDCl}_{3}\right): \delta 2.58(\mathrm{~s}, 1 \mathrm{H}, \mathrm{C} \equiv \mathrm{CH}), 3.93\left(\mathrm{~s}, 3 \mathrm{H}, \mathrm{OCH}_{3}\right), 4.78\left(\mathrm{~d}, J=1.6 \mathrm{~Hz}, 2 \mathrm{H}, \mathrm{OCH}_{2}\right), 6.62(\mathrm{~s}, 1 \mathrm{H}$, H-3), 6.66 (d, $J=8.8 \mathrm{~Hz}, 1 \mathrm{H}, \mathrm{H}-5), 7.32-7.36$ (m, 1H, H-5'), 7.56 (d, J = 15.6 Hz, 1H, =CH), 7.62 $(\mathrm{d}, J=16 \mathrm{~Hz}, 1 \mathrm{H}, \mathrm{CH}=)$ ), $7.81(\mathrm{~d}, J=8.8 \mathrm{~Hz}, 1 \mathrm{H}, \mathrm{H}-6$ ') 7.89 (d, $J=8 \mathrm{~Hz}, 1 \mathrm{H}, \mathrm{H}-6), 8.61(\mathrm{~d}, J=$ $4.4 \mathrm{~Hz}, 1 \mathrm{H}, \mathrm{H}-4$ ') 8.84 (s, 1H, H-2'). ${ }^{13} \mathrm{C} \mathrm{NMR}\left(\mathrm{CDCl}_{3}\right) \delta$ 55.7, 56.6, 76.3, 77.7, 101.7, 108.5, $113.3,122.3,125.7,131.2,136.5,141.0,142.0,148.8,149.5,151.2,166.5,166.9,192.0$. ESI-MS $(m / z): 294(\mathrm{M}+\mathrm{H}) ;$ Anal. $\mathrm{C}_{18} \mathrm{H}_{15} \mathrm{NO}_{3}(\mathrm{C}, \mathrm{H}, \mathrm{N})$.

5.3.12. (E)-3-(4-bromophenyl)-1-(2-methoxy-4-(prop-2-yn-1-yloxy)phenyl)prop-2-en-1-one

(12).

Starting from $36(0.20 \mathrm{~g}, 1.0 \mathrm{mmol})$ and 4-bromobenzaldheyde $(0.20 \mathrm{~g}, 1.1 \mathrm{mmol})$ gave the crude final product 12 that was purified by flash chromatography (petroleum ether/EtOAc 9:1) and then crystallized from ethanol to obtain a yellow solid $(0.35 \mathrm{~g}), 95 \%$ yield, mp 131-133 ${ }^{\circ} \mathrm{C} .{ }^{1} \mathrm{H}$ NMR $\left(\mathrm{CDCl}_{3}\right) \delta 2.59(\mathrm{t}, J=2.4 \mathrm{~Hz}, 1 \mathrm{H}, \mathrm{C} \equiv \mathrm{CH}), 3.92\left(\mathrm{~s}, 3 \mathrm{H}, \mathrm{OCH}_{3}\right), 4.77\left(\mathrm{~d}, J=1.6 \mathrm{~Hz}, 2 \mathrm{H}, \mathrm{OCH}_{2}\right)$, $6.61(\mathrm{~s}, 1 \mathrm{H}, \mathrm{H}-3), 6.65(\mathrm{~d}, J=8.4 \mathrm{~Hz}, 1 \mathrm{H}, \mathrm{H}-5), 7.49(\mathrm{~d}, J=17.2 \mathrm{~Hz}, 1 \mathrm{H},=\mathrm{CH}), 7.53(\mathrm{~d}, J=8.4$ Hz, 2H, H-2' and H-6') 7.61 (d, $J=15.6 \mathrm{~Hz}, 1 \mathrm{H}, \mathrm{CH}=), 7.77$ (d, $J=8.4 \mathrm{~Hz}, 1 \mathrm{H}, \mathrm{H}-6) 8.26$ (d, $J=$ $8.8 \mathrm{~Hz}, 2 \mathrm{H}, \mathrm{H}-3$ ' and H-5'). ${ }^{13} \mathrm{C} \mathrm{NMR}\left(\mathrm{CDCl}_{3}\right) \delta 55.9,56.6,76.2,77.9,99.7,106.2,122.3,124.9$, 127.1, 129.6, 130.0, 132.1, 132.0, 134.9, 140.6, 160.8, 162.0, 190.2. ESI-MS (m/z): $372(\mathrm{M}+\mathrm{H})$; Anal. $\mathrm{C}_{19} \mathrm{H}_{15} \mathrm{BrO}_{3}(\mathrm{C}, \mathrm{H})$.

5.3.13. (E)-1-(2,4-bis(prop-2-yn-1-yloxy)phenyl)-3-(pyridin-4-yl)prop-2-en-1-one (13). Starting from $37(0.23 \mathrm{~g}, 1.0 \mathrm{mmol})$ and 4-pyridinecarboxaldehyde $(0.19 \mathrm{~g}, 1.1 \mathrm{mmol})$ gave the crude final product 13 that was purified by crystallization from EtOH to obtain a yellow solid (0.08 $\mathrm{g}), 27 \%$ yield, mp 156-158 ${ }^{\circ} \mathrm{C} .{ }^{1} \mathrm{H}$ NMR $\left(\mathrm{CDCl}_{3}\right) \delta 2.58-2.60(\mathrm{~m}, 2 \mathrm{H}, \mathrm{C} \equiv \mathrm{CH}), 4.78(\mathrm{~d}, J=2.0 \mathrm{~Hz}, 2 \mathrm{H}$, $\left.\mathrm{OCH}_{2}\right) 4.80\left(\mathrm{~d}, J=2.4 \mathrm{~Hz}, 2 \mathrm{H}, \mathrm{OCH}_{2}\right), 6.69(\mathrm{~d}, J=1.6 \mathrm{~Hz}, 1 \mathrm{H}, \mathrm{H}-3), 6.72(\mathrm{dd}, J=2.0$ and $8.4 \mathrm{~Hz}$, 1H, H-5), 7.46 (d, $J=5.2 \mathrm{~Hz}, 2 \mathrm{H}, \mathrm{H}-2^{\prime}$ and H-6'), 7.57 (d, $\left.J=15.6 \mathrm{~Hz}, 1 \mathrm{H},=\mathrm{CH}\right), 7.73$ (d, $J=15.6$ $\mathrm{Hz}, 1 \mathrm{H}, \mathrm{CH}=), 7.84$ (d, $J=8.8 \mathrm{~Hz}, 1 \mathrm{H}, \mathrm{H}-6), 8.66(\mathrm{~d}, J=4.4 \mathrm{~Hz}, 2 \mathrm{H}, \mathrm{H}-3$ ' and $\mathrm{H}-5$ ' $) .{ }^{13} \mathrm{C} \mathrm{NMR}$ 
503

504

505

506

507

508

509

510

511

512

513

514

515

516

517

518

519

520

521

522

523

524

525

526

$\left(\mathrm{CDCl}_{3}\right) \delta 55.9,56.0,76.2,77.9,100.7,107.6,113.8,118.4,122.4,124.7,131.2,138.5,140.9$, 142.0, 150.5, 166.7, 167.9, 192.1. ESI-MS (m/z): $318(\mathrm{M}+\mathrm{H})$; Anal. $\mathrm{C}_{20} \mathrm{H}_{15} \mathrm{NO}_{3}(\mathrm{C}, \mathrm{H}, \mathrm{N})$.

5.3.14. (E)-1-(2,4-bis(prop-2-yn-1-yloxy)phenyl)-3-(pyridin-3-yl)prop-2-en-1-one (14). Starting from $37(0.23 \mathrm{~g}, 1.0 \mathrm{mmol})$ and 3-pyridinecarboxaldehyde $(0.19 \mathrm{~g}, 1.1 \mathrm{mmol})$ gave the crude final product 14 that was purified by crystallization from ethanol to obtain a yellow solid $(0.23 \mathrm{~g}), 72 \%$ yield, mp 156-158 ${ }^{\circ} \mathrm{C} .{ }^{1} \mathrm{H}$ NMR $\left(\mathrm{CDCl}_{3}\right): \delta 2.58-2.60(\mathrm{~m}, 2 \mathrm{H}, \mathrm{C} \equiv \mathrm{CH}), 4.78(\mathrm{~d}, J=2.0 \mathrm{~Hz}, 2 \mathrm{H}$, $\left.\mathrm{OCH}_{2}\right), 4.80\left(\mathrm{~d}, J=2.4 \mathrm{~Hz}, 2 \mathrm{H}, \mathrm{OCH}_{2}\right), 6.51(\mathrm{~s}, 1 \mathrm{H}, \mathrm{H}-3), 6.53(\mathrm{~d}, J=8.8 \mathrm{~Hz}, 1 \mathrm{H}, \mathrm{H}-5), 7.32-7.36$ (m, 1H, H-5'), 7.62 (d, $J=15.6 \mathrm{~Hz}, 1 \mathrm{H},=\mathrm{CH}), 7.82(\mathrm{~d}, J=16 \mathrm{~Hz}, 1 \mathrm{H}, \mathrm{CH}=), 7.84$ (d, $J=8.8 \mathrm{~Hz}$, 1H, H-6'), 7.79 (d, $J=7.6 \mathrm{~Hz}, 1 \mathrm{H}, \mathrm{H}-6), 8.61$ (d, $J=4.8 \mathrm{~Hz}, 1 \mathrm{H}, \mathrm{H}-4$ '), 8.94 (s, $\left.1 \mathrm{H}, \mathrm{H}-2^{\prime}\right) .{ }^{13} \mathrm{C}$ NMR $\left(\mathrm{CDCl}_{3}\right) \delta 56.3,56.9,76.4,76.7,77.9,101.1,107.2,123.4,127.6,128.5,130.5,131.6,131.7$, 132.9, 141.0, 158.0, 159.2, 160.7, 165.0, 190.0. ESI-MS $(\mathrm{m} / \mathrm{z}): 318(\mathrm{M}+\mathrm{H})$; Anal. $\mathrm{C}_{20} \mathrm{H}_{15} \mathrm{NO}_{3}(\mathrm{C}$, $\mathrm{H}, \mathrm{N})$.

\subsubsection{5. (E)-1-(2,4-bis(prop-2-yn-1-yloxy)phenyl)-3-(4-bromophenyl)prop-2-en-1-one (15)}

Starting from $37(0.23 \mathrm{~g}, 1.0 \mathrm{mmol})$ and 4-bromobenzaldheyde $(0.20 \mathrm{~g}, 1.1 \mathrm{mmol})$ gave the crude final product 15 that was purified by flash chromatography (petroleum ether/EtOAc 9:1) and then crystallized from EtOH to obtain a yellow solid $(0.37 \mathrm{~g}), 95 \%$ yield, mp 123-125 ${ }^{\circ} \mathrm{C}$. ${ }^{1} \mathrm{H}-\mathrm{NMR}$ $\left(\mathrm{CDCl}_{3}\right) \delta 2.57-2.59(\mathrm{~m}, 2 \mathrm{H}, 2 \mathrm{C} \equiv \mathrm{CH}), 4.78\left(\mathrm{~d}, J=8.8 \mathrm{~Hz}, 4 \mathrm{H}, 2 \mathrm{OCH}_{2}\right), 6.70(\mathrm{~s}, 1 \mathrm{H}, \mathrm{H}-3), 6.73(\mathrm{~d}$, $J=8.4 \mathrm{~Hz}, 1 \mathrm{H}, \mathrm{H}-5), 7.46-7.54\left(\mathrm{~m}, 4 \mathrm{H}, \mathrm{H}-2^{\prime}-\mathrm{H}^{-6}{ }^{\prime}\right), 7.56(\mathrm{~d}, J=15.6 \mathrm{~Hz}, 1 \mathrm{H},=\mathrm{CH}), 7.62(\mathrm{~d}, J=16$ $\mathrm{Hz}, 1 \mathrm{H}, \mathrm{CH}=), 7.80(\mathrm{~d}, J=8.4 \mathrm{~Hz}, 1 \mathrm{H}, \mathrm{H}-6) .{ }^{13} \mathrm{C} \mathrm{NMR}\left(\mathrm{CDCl}_{3}\right) \delta 55.8,56.0,76.1,76.3,99.6$, 106.1, 122.8, 124.2, 127.6, 129.6, 131.0, 132.1, 132.8, 134.9, 140.6, 160.3, 162.1, 190.1. ESI-MS $(m / z): 396(\mathrm{M}+\mathrm{H}) ;$ Anal. $\mathrm{C}_{21} \mathrm{H}_{15} \mathrm{BrO}_{3}(\mathrm{C}, \mathrm{H})$.

5.3.16. (E)-1-(2,4-bis(prop-2-yn-1-yloxy)phenyl)-3-(4-fluorophenyl)prop-2-en-1-one (16). Starting from $37(0.23 \mathrm{~g}, 1.0 \mathrm{mmol})$ and 4-fluorobenzaldheyde $(0.14 \mathrm{~g}, 1.1 \mathrm{mmol})$ gave the crude final product 16 that was purified by flash chromatography (petroleum ether/EtOAc 4:1) and then 
5.3.17.

crystallized from EtOH to obtain a yellow solid $(0.30 \mathrm{~g}), 91 \%$ yield, mp $159-161{ }^{\circ} \mathrm{C} .{ }^{1} \mathrm{H}$ NMR $\left(\mathrm{CDCl}_{3}\right) \delta 2.57-2.59(\mathrm{~m}, 2 \mathrm{H}, 2 \mathrm{C} \equiv \mathrm{CH}), 4.77\left(\mathrm{~d}, J=2.4 \mathrm{~Hz}, 2 \mathrm{H}, \mathrm{OCH}_{2}\right), 4.79(\mathrm{~d} . J=2.4 \mathrm{~Hz}, 2 \mathrm{H}$, $\left.\mathrm{OCH}_{2}\right) 6.71$ (s, 1H, H-3), $6.72(\mathrm{~d}, J=2.4 \mathrm{~Hz}, 1 \mathrm{H}, \mathrm{H}-5), 7.06-7.11(\mathrm{~m}, 2 \mathrm{H}, \mathrm{H}-2$ ' and H-6'), 7.48 (d, $J=15.6 \mathrm{~Hz}, 1 \mathrm{H},=\mathrm{CH}), 7.59-7.62\left(\mathrm{~m}, 2 \mathrm{H}, \mathrm{H}-3^{\prime}\right.$ and H-5'), $7.65(\mathrm{~d}, J=16 \mathrm{~Hz}, 1 \mathrm{H}, \mathrm{CH}=), 7.79(\mathrm{~d}, J$ $=9.6 \mathrm{~Hz}, 1 \mathrm{H}, \mathrm{H}-6) .{ }^{13} \mathrm{C} \mathrm{NMR}\left(\mathrm{CDCl}_{3}\right) \delta 56.0,56.6,76.2,76.3,77.7,77.8,101.1,107.2,115.8(\mathrm{~d}, J$ $=22 \mathrm{~Hz}), 123.4,126.8,126.9,130.1(\mathrm{~d}, J=8.5 \mathrm{~Hz}), 131.6,131.7,132.9,141.0,158.1,161.7,165.0$, 190.0. ESI-MS (m/z): $335(\mathrm{M}+\mathrm{H})$; Anal. $\mathrm{C}_{21} \mathrm{H}_{15} \mathrm{FO}_{3}(\mathrm{C}, \mathrm{H}, \mathrm{N})$. (E)-N-(4-(3-(2-methoxy-4-((3-methylbut-2-en-1-yl)oxy)phenyl)-3-oxoprop-1-en-1yl)phenyl)acetamide (17). Starting from $34(0.23 \mathrm{~g}, 1.0 \mathrm{mmol})$ and 4-acetamidobenzaldehyde (0.18 $\mathrm{g}, 1.1 \mathrm{mmol}$ ) gave the crude final product $\mathbf{1 7}$ that was purified by crystallization from EtOH to obtain a yellow solid (0.12 g), 58\% yield, mp 131-133 ${ }^{\circ} \mathrm{C} .{ }^{1} \mathrm{H}$ NMR $\left(\mathrm{CDCl}_{3}\right) \delta 1.78\left(\mathrm{~s}, 3 \mathrm{H}, \mathrm{CH}_{3}\right)$, $1.82\left(\mathrm{~s}, 3 \mathrm{H}, \mathrm{CH}_{3}\right), 2.21\left(\mathrm{~s}, 3 \mathrm{H}, \mathrm{COCH}_{3}\right), 3.90\left(\mathrm{~s}, 3 \mathrm{H}, \mathrm{OCH}_{3}\right), 4.57\left(\mathrm{~d}, J=6.4 \mathrm{~Hz}, 2 \mathrm{H}, \mathrm{OCH}_{2}\right), 5.49-$ $5.54(\mathrm{~m}, 1 \mathrm{H}, \mathrm{CH}), 6.52(\mathrm{~d}, J=2.0 \mathrm{~Hz}, 1 \mathrm{H}, \mathrm{H}-3), 6.57(\mathrm{dd}, J=8.0$ and $2.0 \mathrm{~Hz}, 1 \mathrm{H}, \mathrm{H}-5), 7.23$ (br, 1H, NH), $7.46(\mathrm{~d}, J=16.0 \mathrm{~Hz}, 1 \mathrm{H},=\mathrm{CH}), 7.53(\mathrm{~d}, J=8.0 \mathrm{~Hz}, 2 \mathrm{H}, \mathrm{H}-2$ ' and H-6'), 7.57 (d, $J=8.0$ $\mathrm{Hz}, 2 \mathrm{H}, \mathrm{H}-3^{\prime}$ and $\left.\mathrm{H}^{\prime} 5^{\prime}\right), 7.64$ (d, $\left.J=16.0 \mathrm{~Hz}, 1 \mathrm{H}, \mathrm{CH}=\right), 7.75$ (d, $\left.J=8.2 \mathrm{~Hz}, 1 \mathrm{H}, \mathrm{H}-6\right) .{ }^{13} \mathrm{C}$ NMR $\left(\mathrm{CDCl}_{3}\right) \delta 18.2,23.3,25.8,55.7,65.1,105.8,118.9,121.3,124.5,129.6,131.0,134.2,138.6,145.9$, 161.5, 163.2, 169.9, 188.2. ESI-MS (m/z): $380(\mathrm{M}+\mathrm{H})$; Anal. $\mathrm{C}_{19} \mathrm{H}_{20} \mathrm{O}_{4}(\mathrm{C}, \mathrm{H})$.

5.3.18. (E)-3-(furan-2-yl)-1-(2-methoxy-4-((3-methylbut-2-en-1-yl)oxy)phenyl)prop-2-en-1-one (18). Starting from $34(0.23 \mathrm{~g}, 1.0 \mathrm{mmol})$ and 2-furaldehyde $(0.11 \mathrm{~g}, 1.1 \mathrm{mmol})$ gave the crude final product 18 that was purified by purified by flash chromatography (petroleum ether/EtOAc 4:1) to obtain a brown oil $(0.16 \mathrm{~g}), 51 \%$ yield. ${ }^{1} \mathrm{H} \mathrm{NMR}\left(\mathrm{CDCl}_{3}\right) \delta 1.77\left(\mathrm{~s}, 3 \mathrm{H}, \mathrm{CH}_{3}\right), 1.82\left(\mathrm{~s}, 3 \mathrm{H}, \mathrm{CH}_{3}\right)$, $3.90\left(\mathrm{~s}, 3 \mathrm{H}, \mathrm{OCH}_{3}\right), 4.58\left(\mathrm{~d}, J=6.4 \mathrm{~Hz}, 2 \mathrm{H}, \mathrm{OCH}_{2}\right), 5.47-5.50(\mathrm{~m}, 1 \mathrm{H}, \mathrm{CH}), 6.48-6.51(\mathrm{~m}, 2 \mathrm{H}$, furfuryl), $6.56(\mathrm{~d}, J=1.8 \mathrm{~Hz}, 1 \mathrm{H}, \mathrm{H}-3), 6.64(\mathrm{dd}, J=1.8$ and $8.4 \mathrm{~Hz}, 1 \mathrm{H}, \mathrm{H}-5), 7.26-7.27(\mathrm{~m}, 1 \mathrm{H}$, furfuryl), $7.42(\mathrm{~d}, J=15.6 \mathrm{~Hz}, 1 \mathrm{H},=\mathrm{CH}), 7.48(\mathrm{~d}, J=15.6 \mathrm{~Hz}, 1 \mathrm{H}, \mathrm{CH}=), 7.76(\mathrm{~d}, J=8.2 \mathrm{~Hz}, 1 \mathrm{H}$, $\mathrm{H}-6) .{ }^{13} \mathrm{C} \mathrm{NMR}\left(\mathrm{CDCl}_{3}\right) \delta 18.2,24.3,55.7,64.2,101.2,107.9,112.5,113.9,119.5,120.8,123.4$, 
131.6, 138.9, 143.2, 152.5, 163.4, 168.8, 191.5. ESI-MS $(m / z): 313(\mathrm{M}+\mathrm{H})$; Anal. $\mathrm{C}_{20} \mathrm{H}_{15} \mathrm{NO}_{3}(\mathrm{C}$, $\mathrm{H}, \mathrm{N}$ ).

5.3.19. (E)-1-(2-hydroxy-4-((3-methylbut-2-en-1-yl)oxy)phenyl)-3-phenylprop-2-en-1-one (19) [34]. Reaction of 32 (1.0 mmol, $0.17 \mathrm{~g})$ and benzaldehyde (1.1 mmol, $0.12 \mathrm{~g})$ gave the crude 19 that was purified by crystallization from EtOH to obtain a yellow solid $(0.2 \mathrm{~g}), 64 \%$ yield, mp $92-95{ }^{\circ} \mathrm{C} .{ }^{1} \mathrm{H}$ $\operatorname{NMR}\left(\mathrm{CDCl}_{3}\right) \delta 1.76\left(\mathrm{~s}, 3 \mathrm{H}, \mathrm{CH}_{3}\right), 1.81\left(\mathrm{~s}, 3 \mathrm{H}, \mathrm{CH}_{3}\right), 4.56\left(\mathrm{~d}, J=6.0 \mathrm{~Hz}, 2 \mathrm{H}, \mathrm{OCH}_{2}\right), 5.47(\mathrm{t}, J=$ $6.0 \mathrm{~Hz}, 1 \mathrm{H}, \mathrm{CH}), 6.49$ (dd, $J=2.0$ and $8.4 \mathrm{~Hz}, 1 \mathrm{H}, \mathrm{H}-5), 6.52(\mathrm{~d}, J=1.8 \mathrm{~Hz}, 1 \mathrm{H}, \mathrm{H}-3), 7.43-7.55$ (m, 3H, H-3'-H-5'), $7.60(\mathrm{~d}, J=15.6 \mathrm{~Hz}, 1 \mathrm{H},=\mathrm{CH}), 7.63-7.65(\mathrm{~m}, 2 \mathrm{H}, \mathrm{H}-2$ ' and H-6'), $7.82(\mathrm{~d}, J=$ $8.4 \mathrm{~Hz}, 1 \mathrm{H}, \mathrm{H}-6), 7.89$ (d, $J=15.3 \mathrm{~Hz}, 1 \mathrm{H}, \mathrm{CH}=), 10.45$ (br, $1 \mathrm{H}, \mathrm{OH}) .{ }^{13} \mathrm{C} \mathrm{NMR}\left(\mathrm{CDCl}_{3}\right) \delta 18.6$, 19.5, 65.0, 101.8, 108.2, 113.9, 118.6, 120.5, 128.4, 128.8, 130.7, 130.5, 130.0, 134.2, 138.6, 143.7, 165.0, 166.1, 191.7, (In accordance with previously published spectroscopic data). MS (ESI ${ }^{+}$m/z: $309(\mathrm{M}+\mathrm{H})$; Anal. $\mathrm{C}_{20} \mathrm{H}_{20} \mathrm{O}_{3}(\mathrm{C}, \mathrm{H})$.

5.3.20. (E)-1-(2,4-bis((3-methylbut-2-en-1-yl)oxy)phenyl)-3-phenylprop-2-en-1-one (21). Reaction of 35 (1.0 mmol, $0.29 \mathrm{~g})$ and benzaldehyde (1.1 mmol, $0.12 \mathrm{~g})$ gave the crude 21 that was purified by flash chromatography (petroleum ether/EtOAc 9.75:0.25) to obtain a white oil (0.04 g), 10\% yield. ${ }^{1} \mathrm{H}$ NMR $\left(\mathrm{CDCl}_{3}\right) \delta 1.76\left(\mathrm{~s}, 3 \mathrm{H}, \mathrm{CH}_{3}\right), 1.82\left(\mathrm{~s}, 3 \mathrm{H}, \mathrm{CH}_{3}\right), 1.85\left(\mathrm{~s}, 3 \mathrm{H}, \mathrm{CH}_{3}\right), 1.89(\mathrm{~s}, 3 \mathrm{H}$, $\left.\mathrm{CH}_{3}\right), 4.51\left(\mathrm{~d}, J=6.0 \mathrm{~Hz}, 2 \mathrm{H}, \mathrm{OCH}_{2}\right), 4.58\left(\mathrm{~d}, J=6.0 \mathrm{~Hz}, 2 \mathrm{H}, \mathrm{OCH}_{2}\right), 5.47-5.61(\mathrm{~m}, 2 \mathrm{H}, \mathrm{CH}), 6.47$ (d, $J=2.0,1 \mathrm{H}, \mathrm{H}-3), 6.61$ (dd, $J=2.0$ and $8.4 \mathrm{~Hz}, 1 \mathrm{H}, \mathrm{H}-5), 7.38-7.42$ (m, 3H, H-3'-H-5'), 7.637.67 (m, 2H, H-2' and H-6'), 7.69 (d, $J=15.6 \mathrm{~Hz}, 1 \mathrm{H},=\mathrm{C}), 7.70$ (d, J = 8.4 Hz, 1H, H-6), 7.81 (d, $J$ $=15.3 \mathrm{~Hz}, 1 \mathrm{H}, \mathrm{C}=) .{ }^{13} \mathrm{C} \mathrm{NMR}\left(\mathrm{CDCl}_{3}\right) \delta 18.6,18.7,20.5,20.7,24.5,24.8,65.1,65.4,101.8,107.3$, 118.6, 119.6, 123.5, 128.1, 128.4, 128.6, 135.5, 138.0, 145.2, 162.4, 168.7, 191.9. ESI-MS (m/z): $378(\mathrm{M}+\mathrm{H})$; Anal. $\mathrm{C}_{25} \mathrm{H}_{28} \mathrm{O}_{3}(\mathrm{C}, \mathrm{H})$.

5.3.21. (E)-3-(4-fluorophenyl)-1-(2-methoxy-4-((3-methylbut-2-en-1-yl)oxy)phenyl)prop-2-en-1-one (22). Starting from $34(0.23 \mathrm{~g}, 1.0 \mathrm{mmol})$ and 4-fluorobenzaldheyde $(0.14 \mathrm{~g}, 1.1 \mathrm{mmol})$ gave the crude final product $\mathbf{2 2}$ that was purified by flash chromatography (petroleum ether/EtOAc 9:1) and 
then crystallized from EtOH to obtain a white solid $(0.12 \mathrm{~g}), 35 \%$ yield, mp $81-83{ }^{\circ} \mathrm{C} .{ }^{1} \mathrm{H}$ NMR $\left(\mathrm{CDCl}_{3}\right) \delta 1.78\left(\mathrm{~s}, 3 \mathrm{H}, \mathrm{CH}_{3}\right), 1.83\left(\mathrm{~s}, 3 \mathrm{H}, \mathrm{CH}_{3}\right), 3.91\left(\mathrm{~s}, 3 \mathrm{H}, \mathrm{OCH}_{3}\right), 4.59\left(\mathrm{~d}, J=6.4 \mathrm{~Hz}, 2 \mathrm{H}, \mathrm{OCH}_{2}\right)$, 5.49-5.53 (m, 1H, CH), $6.53(\mathrm{~d}, J=1.6 \mathrm{~Hz}, 1 \mathrm{H}, \mathrm{H}-3), 6.58(\mathrm{dd}, J=1.6 \mathrm{~Hz}$ and $8.0 \mathrm{~Hz}, 1 \mathrm{H}, \mathrm{H}-5)$, 7.06-7.11 (m, 2H, H-2' and H-6'), $7.46(\mathrm{~d}, J=16.0 \mathrm{~Hz}, 1 \mathrm{H},=\mathrm{CH}), 7.57-7.60\left(\mathrm{~m}, 2 \mathrm{H}, \mathrm{H}-3^{\prime}\right.$ and H5'), $7.65(\mathrm{~d}, J=16.0 \mathrm{~Hz}, 1 \mathrm{H}, \mathrm{CH}=), 7.76(\mathrm{~d}, J=8.8 \mathrm{~Hz}, 1 \mathrm{H}, \mathrm{H}-6) .{ }^{13} \mathrm{C}$ NMR $\left(\mathrm{CDCl}_{3}\right) \delta 18.2,25.8$, 55.7, 65.1, 103.8, 107.4, 118.9, $119.3(\mathrm{~d}, J=22 \mathrm{~Hz}), 124.6,130.0(\mathrm{~d}, J=8.5 \mathrm{~Hz}), 131.2,138.4$, 145.9, 162.7, 168.2, 193.4. ESI-MS (m/z): $341(\mathrm{M}+\mathrm{H})$; Anal. $\mathrm{C}_{21} \mathrm{H}_{21} \mathrm{FO}_{3}(\mathrm{C}, \mathrm{H})$.

5.3.22. (E)-1-(2-methoxy-4-((3-methylbut-2-en-1-yl)oxy)phenyl)-3-(4-methoxyphenyl)prop-2-en-1one (23). Starting from $34(0.23 \mathrm{~g}, 1.0 \mathrm{mmol})$ 4-methoxybenzaldheyde $(0.14 \mathrm{~g}, 1.1 \mathrm{mmol})$ gave the crude final product $\mathbf{2 3}$ that was purified by flash chromatography (petroleum ether/EtOAc 4:1) and then crystallized from EtOH to obtain a yellow solid $(0.23 \mathrm{~g}), 66 \%$ yield, mp $62-64{ }^{\circ} \mathrm{C} .{ }^{1} \mathrm{H}$ NMR $\left(\mathrm{CDCl}_{3}\right) \delta 1.78\left(\mathrm{~s}, 3 \mathrm{H}, \mathrm{CH}_{3}\right), 1.83\left(\mathrm{~s}, 3 \mathrm{H}, \mathrm{CH}_{3}\right), 3.86\left(\mathrm{~s}, 3 \mathrm{H}, \mathrm{OCH}_{3}\right), 3.90\left(\mathrm{~s}, 3 \mathrm{H}, \mathrm{OCH}_{3}\right), 4.58(\mathrm{~d}, J$ $\left.=7.2 \mathrm{~Hz}, 2 \mathrm{H}, \mathrm{OCH}_{2}\right), 5.49-5.53(\mathrm{~m}, 1 \mathrm{H}, \mathrm{CH}), 6.53(\mathrm{~d}, J=2.0 \mathrm{~Hz}, 1 \mathrm{H}, \mathrm{H}-3), 6.57(\mathrm{dd}, J=2.0 \mathrm{~Hz}$ and $8.8 \mathrm{~Hz}, 1 \mathrm{H}, \mathrm{H}-5), 6.90-6.95$ (m, 2H, H-3' and H-5'), 7.40 (d, $J=16.0 \mathrm{~Hz}, 1 \mathrm{H},=\mathrm{CH}), 7.54-7.57$ (m, 2H, H-2' and H-6'), $7.66(\mathrm{~d}, J=15.6 \mathrm{~Hz}, 1 \mathrm{H}, \mathrm{CH}=), 7.74(\mathrm{~d}, J=8.8 \mathrm{~Hz}, 1 \mathrm{H}, \mathrm{H}-6) .{ }^{13} \mathrm{C}$ NMR $\left(\mathrm{CDCl}_{3}\right) \delta 18.2,24.8,55.7,64.8,64.0,100.9,107.8,118.9,122.5,126.2,127.8,128.7,132.8,135.5$ 141.9, 159.4, 160.4, 162.5, 190.1. ESI-MS (m/z): $353(\mathrm{M}+\mathrm{H})$; Anal. $\mathrm{C}_{22} \mathrm{H}_{24} \mathrm{O}_{4}(\mathrm{C}, \mathrm{H})$.

5.3.23. (E)-3-(3,4-dimethoxyphenyl)-1-(2-methoxy-4-((3-methylbut-2-en-1-yl)oxy)phenyl)prop-2-en1-one (24). Starting from 34 (0.23 g, $1.0 \mathrm{mmol})$ and 3,4-dimethoxybenzaldheyde (0.18 g, $1.1 \mathrm{mmol})$ gave the crude final product $\mathbf{2 4}$ that was purified by flash chromatography (petroleum ether/EtOAc 4:1) and then crystallized from DCM/petroleum ether to obtain a yellow solid ( $0.29 \mathrm{~g}), 77 \%$ yield, mp 83-85 ${ }^{\circ} \mathrm{C} .{ }^{1} \mathrm{H}$ NMR $\left(\mathrm{CDCl}_{3}\right) \delta 1.78\left(\mathrm{~s}, 3 \mathrm{H}, \mathrm{CH}_{3}\right), 1.83\left(\mathrm{~s}, 3 \mathrm{H}, \mathrm{CH}_{3}\right), 3.90\left(\mathrm{~s}, 6 \mathrm{H}, \mathrm{OCH}_{3}\right), 3.93$ (s, $\left.3 \mathrm{H}, \mathrm{OCH}_{3}\right), 4.59\left(\mathrm{~d}, J=7.4 \mathrm{~Hz}, 2 \mathrm{H}, \mathrm{OCH}_{2}\right), 5.48-5.52(\mathrm{~m}, 1 \mathrm{H}, \mathrm{CH}), 6.54(\mathrm{~s}, 1 \mathrm{H}, \mathrm{H}-3), 6.58(\mathrm{~d}, J=$ $8.4 \mathrm{~Hz}, 1 \mathrm{H}, \mathrm{H}-5), 6.89$ (d, $J=8.4 \mathrm{~Hz}, 1 \mathrm{H}, \mathrm{H}-5$ ') 7.13 (d, $\left.J=2.1,1 \mathrm{H}, \mathrm{H}-2^{\prime}\right), 7.20$ (dd, $J=8.4$ and $2.1 \mathrm{~Hz}, 1 \mathrm{H}, \mathrm{H}-6$ ') $7.37(\mathrm{~d}, J=15.6 \mathrm{~Hz}, 1 \mathrm{H},=\mathrm{CH}), 7.63(\mathrm{~d}, J=15.6 \mathrm{~Hz}, 1 \mathrm{H}, \mathrm{CH}=), 7.73(\mathrm{~d}, J=8.8$ 
602

603

604

605

606

607

608

609

610

611

612

613

614

615

616

617

618

619

620

621

622

623

624

625

$\mathrm{Hz}, 1 \mathrm{H}, \mathrm{H}-6) .{ }^{13} \mathrm{C} \mathrm{NMR}\left(\mathrm{CDCl}_{3}\right) \delta 18.2,24.8,55.7,56.2,64.8,64.0,100.9,107.8,118.5,122.5$, 125.3, 127.8, 132.1, 134.4, 141.9, 159.4, 160.4, 161.4, 162.5, 190.4. ESI-MS $(\mathrm{m} / z): 383(\mathrm{M}+\mathrm{H})_{\text {s }}$ Anal. $\mathrm{C}_{23} \mathrm{H}_{26} \mathrm{O}_{5}(\mathrm{C}, \mathrm{H})$.

5.3.24. (E)-1-(2-methoxy-4-(prop-2-yn-1-yloxy)phenyl)-3-(4-nitrophenyl)prop-2-en-1-one

(25).

Starting from $36(0.20 \mathrm{~g}, 1.0 \mathrm{mmol})$ and 4-nitrobenzaldheyde $(0.17 \mathrm{~g}, 1.1 \mathrm{mmol})$ gave the crude final product 25 that was purified by crystallization from ethanol to obtain a white solid $(0.22 \mathrm{~g})$, $67 \%$ yield, mp $178-180^{\circ} \mathrm{C} .{ }^{1} \mathrm{H}$ NMR $\left(\mathrm{CDCl}_{3}\right) \delta 2.59(\mathrm{t}, J=2.4 \mathrm{~Hz}, 1 \mathrm{H}, \mathrm{C} \equiv \mathrm{CH}), 3.94\left(\mathrm{~s}, 3 \mathrm{H}, \mathrm{OCH}_{3}\right)$, $4.78\left(\mathrm{~d}, J=2.4 \mathrm{~Hz}, 2 \mathrm{H}, \mathrm{OCH}_{2}\right), 6.61(\mathrm{~d}, J=2.0 \mathrm{~Hz}, 1 \mathrm{H}, \mathrm{H}-3), 6.67(\mathrm{dd}, J=2.0$ and $8.4 \mathrm{~Hz}, 1 \mathrm{H}, \mathrm{H}-$ 5), $7.64(\mathrm{~d}, J=16.0 \mathrm{~Hz}, 1 \mathrm{H},=\mathrm{CH}), 7.70(\mathrm{~d}, J=16.0 \mathrm{~Hz}, 1 \mathrm{H}, \mathrm{CH}=), 7.73\left(\mathrm{~d}, J=8.4 \mathrm{~Hz}, 2 \mathrm{H}, \mathrm{H}-2^{\prime}\right.$ and H-6'), 7.82 (d, $J=8.4 \mathrm{~Hz}, 1 \mathrm{H}, \mathrm{H}-6), 8.26$ (d, $J=8.8 \mathrm{~Hz}, 2 \mathrm{H}, \mathrm{H}-3$ ' and H-5'). ${ }^{13} \mathrm{C}$ NMR $\left(\mathrm{CDCl}_{3}\right) \delta 55.7,56.5,77.7,105.8,121.3,124.1,128.6,131.0,133.2,138.2,160.7,164.2,183.2$. ESI-MS (m/z): $338(\mathrm{M}+\mathrm{H})$; Anal. $\mathrm{C}_{19} \mathrm{H}_{15} \mathrm{NO}_{5}(\mathrm{C}, \mathrm{H}, \mathrm{N})$.

5.3.25. (E)-1-(2,4-bis(prop-2-yn-1-yloxy)phenyl)-3-(4-nitrophenyl)prop-2-en-1-one (26). Starting from $37(0.23 \mathrm{~g}, 1.0 \mathrm{mmol})$ and 4-nitrobenzaldheyde $(0.17 \mathrm{~g}, 1.1 \mathrm{mmol})$ gave the crude final product 26 that was purified by flash chromatography (petroleum ether/EtOAc 9:1) and then crystallized from ethanol to obtain a yellow solid $(0.37 \mathrm{~g}), 95 \%$ yield, mp $186-188{ }^{\circ} \mathrm{C} .{ }^{1} \mathrm{H}$ NMR $\left(\mathrm{CDCl}_{3}\right) \delta 2.58-2.60(\mathrm{~m}, 2 \mathrm{H}, \mathrm{C} \equiv \mathrm{CH}), 4.75\left(\mathrm{~d}, J=2.4 \mathrm{~Hz}, 2 \mathrm{H}, \mathrm{OCH}_{2}\right), 4.78(\mathrm{~d}, J=2.4 \mathrm{~Hz}, 2 \mathrm{H}$, $\left.\mathrm{OCH}_{2}\right) 6.66(\mathrm{~d}, J=2.0 \mathrm{~Hz}, 1 \mathrm{H}, \mathrm{H}-3), 6.70(\mathrm{dd}, J=2.0$ and $8.8 \mathrm{~Hz}, 1 \mathrm{H}, \mathrm{H}-5), 7.60$ (d, $J=15.6 \mathrm{~Hz}$, $1 \mathrm{H},=\mathrm{CH}), 7.66(\mathrm{~d}, J=16 \mathrm{~Hz}, 1 \mathrm{H}, \mathrm{CH}=), 7.74\left(\mathrm{~d}, J=8.8 \mathrm{~Hz}, 2 \mathrm{H}, \mathrm{H}-2^{\prime}\right.$ and H-6') $7.83(\mathrm{~d}, J=8.4$ $\mathrm{Hz}, 1 \mathrm{H}, \mathrm{H}-6), 8.23\left(\mathrm{~d}, J=8.8 \mathrm{~Hz}, 2 \mathrm{H}, \mathrm{H}-3^{\prime}\right.$ and $\left.\mathrm{H}-5^{\prime}\right) .{ }^{13} \mathrm{C} \mathrm{NMR}\left(\mathrm{CDCl}_{3}\right) \delta$ 55.7, 55.9, 76.2, 76.6, 77.7, 77.8, 101.8, 107.3, 123.1, 127.7, 130.5, 133.2, 138.2, 162.8, 164.4, 187.2. ESI-MS (m/z): 362 $(\mathrm{M}+\mathrm{H})$ Anal. $\mathrm{C}_{21} \mathrm{H}_{15} \mathrm{NO}_{5}(\mathrm{C}, \mathrm{H}, \mathrm{N})$.

5.3.26. (E)-1-(2-methoxy-4-(prop-2-yn-1-yloxy)phenyl)-3-(3,4,5-trimethoxyphenyl)prop-2-en-1-one (27) Starting from $36(0.20 \mathrm{~g}, 1.0 \mathrm{mmol})$ and 3,4,5-trimethoxybenzaldheyde $(0.21 \mathrm{~g}, 1.1 \mathrm{mmol})$ 
626

627

628

629

630

631

632

633

634

635

636

637

638

639

640

641

642

643

644

645

646

647

648

649

gave the crude final product 27 that was purified by crystallization from EtOH to obtain a yellow solid (0.27 g), 73\% yield, mp 106-108 ${ }^{\circ} \mathrm{C} .{ }^{1} \mathrm{H} \mathrm{NMR}\left(\mathrm{CDCl}_{3}\right) \delta 2.58(\mathrm{~s}, 1 \mathrm{H}, \mathrm{C} \equiv \mathrm{CH}), 3.86(\mathrm{~s}, 3 \mathrm{H}$, $\left.\mathrm{OCH}_{3}\right), 3.94\left(\mathrm{~s}, 3 \mathrm{H}, \mathrm{OCH}_{3}\right), 4.75\left(\mathrm{~d}, J=2.0 \mathrm{~Hz}, 2 \mathrm{H}, \mathrm{OCH}_{2}\right), 6.65(\mathrm{~s}, 1 \mathrm{H}, \mathrm{H}-3), 6.67(\mathrm{~d}, J=8.4 \mathrm{~Hz}$, 1H, H-5), 6.81 (s, 2H, H-3' e H-5'), 7.37 (d, $J=15.6 \mathrm{~Hz}, 1 \mathrm{H},=\mathrm{CH}), 7.58$ (d, J = 8.8 Hz, 2H, H-2' and H-6'), $7.64(\mathrm{~d}, J=15.6 \mathrm{~Hz}, 1 \mathrm{H}, \mathrm{CH}=), 7.78(\mathrm{~d}, J=8.8 \mathrm{~Hz}, 1 \mathrm{H}, \mathrm{H}-6) .{ }^{13} \mathrm{C} \mathrm{NMR}\left(\mathrm{CDCl}_{3}\right) \delta 55.8$, 55.9, 56.0, 56.2, 56.3, 76.2, 76.6, 77.8. 77.9. 100.9, 107.8, 110.4, 118.5, 123.0, 123.6, 125.8, 131.0, 132.8, 142.5, 9 149.2, 157.8, 162.2, 190.5. ESI-MS (m/z): $382(\mathrm{M}+\mathrm{H})$; Anal. $\mathrm{C}_{22} \mathrm{H}_{22} \mathrm{O}_{6}(\mathrm{C}, \mathrm{H}, \mathrm{N})$.

5.3.27. (E)-3-(3,4-dimethoxyphenyl)-1-(2-methoxy-4-(prop-2-yn-1-yloxy)phenyl)prop-2-en-1-one (28). Starting from $37(0.23 \mathrm{~g}, 1.0 \mathrm{mmol})$ and 3,4-dimethoxybenzaldheyde $(0.18 \mathrm{~g}, 1.1 \mathrm{mmol})$ gave the crude final product $\mathbf{2 8}$ that was purified by flash chromatography (petroleum ether/EtOAc 9:1) and then crystallized from EtOH to obtain a yellow solid $(0.22 \mathrm{~g}), 69 \%$ yield, mp $130-132{ }^{\circ} \mathrm{C} .{ }^{1} \mathrm{H}$ $\operatorname{NMR}\left(\mathrm{CDCl}_{3}\right) \delta 2.58(\mathrm{~s}, 1 \mathrm{H}, \mathrm{C} \equiv \mathrm{CH}), 3.90\left(\mathrm{~s}, 6 \mathrm{H}, \mathrm{OCH}_{3}\right), 3.93\left(\mathrm{~s}, 3 \mathrm{H}, \mathrm{OCH}_{3}\right), 4.76\left(\mathrm{~s}, 2 \mathrm{H}, \mathrm{OCH}_{2}\right)$, 6.60 (s, 1H, H-3) 6.64 (d, J = 8.4 Hz, 1H, H-5), 6.88 (d, J=8.4 Hz, 1H, H-5'), 7.12 (d, J = 2.2 Hz, 1H, H-2'), 7.19 (dd, $J=8.0$ and $2.2 \mathrm{~Hz}, 1 \mathrm{H}, \mathrm{H}-6$ ') 7.33 (d, $J=15.6 \mathrm{~Hz}, 1 \mathrm{H},=\mathrm{CH}), 7.62(\mathrm{~d}, J=$ $15.6 \mathrm{~Hz}, 1 \mathrm{H}, \mathrm{CH}=), 7.72(\mathrm{~d}, J=8.0 \mathrm{~Hz}, 1 \mathrm{H}, \mathrm{H}-6) .{ }^{13} \mathrm{C} \mathrm{NMR}\left(\mathrm{CDCl}_{3}\right) \delta 55.7,55.8,56.2,56.5,76.7$, $77.9,101.1,107.1,110.0,111.4,123.6,123.9,125.8,127.3,131.8,142.7,147.1,154.5,157.8$, 161.4, 190.4. ESI-MS (m/z): $353(\mathrm{M}+\mathrm{H})$; Anal. $\mathrm{C}_{21} \mathrm{H}_{20} \mathrm{O}_{5}(\mathrm{C}, \mathrm{H})$.

5.3.28. (E)-1-(2,4-bis(prop-2-yn-1-yloxy)phenyl)-3-(3,4,5-trimethoxyphenyl)prop-2-en-1-one (29).

Starting from $37(0.23 \mathrm{~g}, 1 \mathrm{mmol})$ and 3,4,5-trimethoxybenzaldheyde $(0.21 \mathrm{~g}, 1.1 \mathrm{mmol})$ gave the crude final product $\mathbf{2 9}$ that was purified by crystallization from ethanol to obtain a yellow solid (0.27 g), 67\% yield, mp 147-138 ${ }^{\circ} \mathrm{C} .{ }^{1} \mathrm{H}$ NMR $\left(\mathrm{CDCl}_{3}\right) \delta 2.55-2.58(\mathrm{~m}, 2 \mathrm{H}, \mathrm{C} \equiv \mathrm{CH}), 3.94(\mathrm{~s}, 6 \mathrm{H}$, $\left.\mathrm{OCH}_{3}\right), 3.97\left(\mathrm{~s}, 3 \mathrm{H}, \mathrm{OCH}_{3}\right), 4.77-4.79\left(\mathrm{~m}, 4 \mathrm{H}, \mathrm{OCH}_{2}\right), 6.71(\mathrm{~d}, J=2.2 \mathrm{~Hz}, 1 \mathrm{H}, \mathrm{H}-3) 6.88(\mathrm{dd}, J=$ 8.4 and $2.0 \mathrm{~Hz}, 1 \mathrm{H}, \mathrm{H}-5), 6.81$ (s, 2H, H-2' and H-6'), $7.42(\mathrm{~d}, J=15.6 \mathrm{~Hz}, 1 \mathrm{H},=\mathrm{CH}), 7.63(\mathrm{~d}, J=$ $16.0 \mathrm{~Hz}, 1 \mathrm{H}, \mathrm{CH}=), 7.81(\mathrm{~d}, J=8.8 \mathrm{~Hz}, 1 \mathrm{H}, \mathrm{H}-6) .{ }^{13} \mathrm{C} \mathrm{NMR}\left(\mathrm{CDCl}_{3}\right) \delta 55.8,55.9,56.0,56.4,56.5$, 
650

651

652

653

654

655

656

657

658

659

660

661

662

663

664

665

666

667

668

669

670

671

672

673

76.2, 76.7, 77.8, 77.9, 101.1, 107.1, 110.2, 111.3, 123.7, 125.4, 128.3, 132.5, 142.7, 149.1, 150.8, 151.1, 157.8, 161.4, 190.3. ESI-MS (m/z): $407(\mathrm{M}+\mathrm{H})$; Anal. $\mathrm{C}_{24} \mathrm{H}_{22} \mathrm{O}_{6}(\mathrm{C}, \mathrm{H})$.

5.3.29. (E)-1-(2,4-bis(prop-2-yn-1-yloxy)phenyl)-3-(3,4-dimethoxyphenyl)prop-2-en-1-one (30).

Starting from $37(0.23 \mathrm{~g}, 1.0 \mathrm{mmol})$ and 3,4-dimethoxybenzaldheyde $(0.18 \mathrm{~g}, 1.1 \mathrm{mmol})$ gave the crude final product $\mathbf{3 0}$ that was purified by flash chromatography (petroleum ether/EtOAc 4:1) and then crystallized from EtOH to obtain a yellow solid $(0.24 \mathrm{~g}), 65 \%$ yield, mp $137-139{ }^{\circ} \mathrm{C} .{ }^{1} \mathrm{H} \mathrm{NMR}$ $\left(\mathrm{CDCl}_{3}\right) \delta 2.55-2.58(\mathrm{~m}, 2 \mathrm{H}, \mathrm{C} \equiv \mathrm{CH}), 3.94\left(\mathrm{~s}, 6 \mathrm{H}, \mathrm{OCH}_{3}\right), 4.77-4.79\left(\mathrm{~m}, 4 \mathrm{H}, \mathrm{OCH}_{2}\right), 6.71(\mathrm{~d}, J=$ $2.2 \mathrm{~Hz}, 1 \mathrm{H}, \mathrm{H}-3) 6.88(\mathrm{~d}, J=8.4$ and $2.2 \mathrm{~Hz}, 1 \mathrm{H}, \mathrm{H}-5), 7.16(\mathrm{~d}, J=8.2 \mathrm{~Hz}, 1 \mathrm{H}, \mathrm{H}-5$ '), $7.20(\mathrm{~d}, J=$ $\left.2.0 \mathrm{~Hz}, 1 \mathrm{H}, \mathrm{H}-2^{\prime}\right), 7.22(\mathrm{dd}, J=8.0$ and $2.2 \mathrm{~Hz}, 1 \mathrm{H}, \mathrm{H}-6$ '), 7.40 (d, $J=15.6 \mathrm{~Hz}, 1 \mathrm{H},=\mathrm{CH}), 7.64$ (d, $J=16.0 \mathrm{~Hz}, 1 \mathrm{H}, \mathrm{CH}=), 7.75(\mathrm{~d}, J=8.8 \mathrm{~Hz}, 1 \mathrm{H}, \mathrm{H}-6) .{ }^{13} \mathrm{C} \mathrm{NMR}\left(\mathrm{CDCl}_{3}\right) \delta 55.8,55.9,56.0,56.5$, 76.2, 76.7, 77.8, 77.9, 101.1, 107.1, 110.0, 111.1, 122.9, 123.8, 125.1, 128.3, 132.6, 142.7, 149.1, 151.1, 157.8, 161.4, 190.4. ESI-MS (m/z): $377(\mathrm{M}+\mathrm{H})$; Anal. $\mathrm{C}_{23} \mathrm{H}_{20} \mathrm{O}_{5}(\mathrm{C}, \mathrm{H})$.

\subsubsection{0.

Starting from $37(0.23 \mathrm{~g}, 1.0 \mathrm{mmol})$ and 4-methoxybenzaldheyde $(0.14 \mathrm{~g}, 1.1 \mathrm{mmol})$ gave the crude final product 31 that was purified by flash chromatography (petroleum ether/EtOAc 9:1) and then crystallized from EtOH to obtain an orange solid $(0.20 \mathrm{~g}), 59 \%$ yield; mp $120-122{ }^{\circ} \mathrm{C}$. ${ }^{1} \mathrm{H}$ NMR $\left(\mathrm{CDCl}_{3}\right) \delta 2.57-2.60(\mathrm{~m}, 2 \mathrm{H}, \mathrm{C} \equiv \mathrm{CH}), 3.86\left(\mathrm{~s}, 3 \mathrm{H}, \mathrm{OCH}_{3}\right), 4.76\left(\mathrm{~d}, J=1.6 \mathrm{~Hz}, 2 \mathrm{H}, \mathrm{OCH}_{2}\right), 4.78(\mathrm{~d}$, $\left.J=2.0 \mathrm{~Hz}, 2 \mathrm{H}, \mathrm{OCH}_{2}\right) 6.70(\mathrm{~d}, J=2.2 \mathrm{~Hz}, 1 \mathrm{H}, \mathrm{H}-3), 6.72(\mathrm{~d}, J=8.2 \mathrm{~Hz}, 1 \mathrm{H}, \mathrm{H}-5), 6.92(\mathrm{~d}, J=8.4$ Hz, 2H, H-3' and H-5'), 7.42 (d, $J=15.6 \mathrm{~Hz}, 1 \mathrm{H},=\mathrm{CH}), 7.58$ (d, $J=8.4 \mathrm{~Hz}, 2 \mathrm{H}, \mathrm{H}-2^{\prime}$ and H-6'), $7.66(\mathrm{~d}, J=15.6 \mathrm{~Hz}, 1 \mathrm{H}, \mathrm{CH}=), 7.76(\mathrm{~d}, J=8.8 \mathrm{~Hz}, 1 \mathrm{H}, \mathrm{H}-6) .{ }^{13} \mathrm{C} \mathrm{NMR}\left(\mathrm{CDCl}_{3}\right) \delta 55.9,56.0$, 56.5, 76.2, 76.7, 77.7, 77.9, 101.1, 107.1, 110.0, 111.1, 122.4, 123.7, 125.2, 128.9, 132.7, 132.8, 142.7, 149.8, 157.8, 161.2, 190.5. ESI-MS (m/z): $345(\mathrm{M}+\mathrm{H})$; Anal. $\mathrm{C}_{20} \mathrm{H}_{15} \mathrm{NO}_{3}(\mathrm{C}, \mathrm{H}, \mathrm{N})$.

\subsubsection{2-cinnamoyl-5-((3-methylbut-2-en-1-yl)oxy)phenyl acetate (20).Compound 19 (0.31 g, 1.0} mmol) was reacted with acetic anhydride $(10 \mathrm{~mL})$ and the mixture was heated under reflux for $4 \mathrm{hr}$ 
and then poured into ice/water. The solid was collected and crystallized from EtOH to give $\mathbf{1 9}$ as white solid $(0.23 \mathrm{~g}), 66 \%$ yield, mp $121-122{ }^{\circ} \mathrm{C} .{ }^{1} \mathrm{H} \mathrm{NMR}\left(\mathrm{CDCl}_{3}\right) \delta 1.79\left(\mathrm{~s}, 3 \mathrm{H}, \mathrm{CH}_{3}\right), 1.82(\mathrm{~s}$, $\left.3 \mathrm{H}, \mathrm{CH}_{3}\right), 2.35\left(\mathrm{~s}, 3 \mathrm{H}, \mathrm{COCH}_{3}\right), 4.56\left(\mathrm{~d}, J=6.0 \mathrm{~Hz}, 2 \mathrm{H}, \mathrm{OCH}_{2}\right), 5.47-5.50(\mathrm{~m}, 1 \mathrm{H},=\mathrm{CH}), 6.41(\mathrm{~d}, J$ $=2.0,1 \mathrm{H}, \mathrm{H}-5), 6.60(\mathrm{dd}, J=1.8$ and $8.4 \mathrm{~Hz}, 1 \mathrm{H}, \mathrm{H}-3), 7.27(\mathrm{~d}, J=15.6 \mathrm{~Hz}, 1 \mathrm{H},=\mathrm{CH}), 7.33-7.45$ (m, 3H, H-3', H-4', H-5'), 7.53-7.61 (m, 2H, H-2' and H-6'), 7.65 (d, J=15.3 Hz, 1H, =CH), 7.78 $(\mathrm{d}, J=8.4 \mathrm{~Hz}, 1 \mathrm{H}, \mathrm{H}-6) .{ }^{13} \mathrm{C} \mathrm{NMR}\left(\mathrm{CDCl}_{3}\right) \delta 18.61,20.5,24.5,65.1,104.8,118.6,113.6,118.6$, 118.9, 120.5, 127.7, 128.2, 139.7, 135.9, 138.0, 145.2, 154.4, 154.7, 166.0, 169.11, 191.7. ESI-MS $(m / z): 351(\mathrm{M}+\mathrm{H})$; Anal. $\mathrm{C}_{20} \mathrm{H}_{20} \mathrm{O}_{3}(\mathrm{C}, \mathrm{H})$.

\subsection{Parasitology.}

5.4.1. Parasites. Promastigote forms of a L. donovani reference strain (MHOM/NP/02/BPK282/0c14), L. major reference strain (MHOM/SU/73/5-ASKH), L. tropica reference strain (MHOM/SU/74/K27), L. infantum reference strain (MHOM/ TN/ 80/ IPT1) were cultured at $26^{\circ} \mathrm{C}$ in $\mathrm{HOMEM}$ (Gibco Thermo Fisher Scientific Inc., Waltham, USA), a liquid custom made medium supplemented with $20 \%$ foetal bovine serum (FBS, EuroClone SpA, Milan, Italy) and 1\% penicillin-streptomycin (EuroClone SpA).

5.4.2. Cell cultures. THP-1 cells (human leukemia monocytic cell line) were cultured at $37{ }^{\circ} \mathrm{C}$ in RPMI-1640 (EuroClone SpA) liquid medium supplemented with 10\% FBS (EuroClone SpA), 1\% levoglutamine (EuroClone SpA), Mercaptoethanol (Gibco) $50 \mu \mathrm{M}, 1 \%$ penicillin-streptomycin. Vero cells (kidney of African green monkey epithelial cell line) were cultured at $37{ }^{\circ} \mathrm{C}$ in MEM liquid medium supplemented with 10\% FBS (EuroClone SpA), 1\% levoglutamine (EuroClone $\mathrm{SpA}), 1 \%$ penicillin-streptomycin (EuroClone SpA).

5.4.3. Promastigote growth inhibition assay. The late $\log /$ stationary phase of promastigotes were seeded with complete HOMEM medium at $10^{6} / \mathrm{mL}$ in 96 -well plates and incubated with tested compounds at a range concentration of $40 \mu \mathrm{M}-1.6 \mu \mathrm{M}$ in a $26{ }^{\circ} \mathrm{C}$ incubator for $72 \mathrm{~h}$. The antileishmanial drug amphotericin B was used as standard drug (positive control). Each experiment 
was performed in duplicate. Stock solution of the compounds was $8 \mathrm{mM}$ in DMSO. To estimate the concentration at which the compounds caused $50 \%$ inhibition of growth $\left(\mathrm{IC}_{50}\right)$, the AlamarBlue assay was employed (Life Technologies, Thermo Fisher Scientific Inc., Waltham, USA). The AlamarBlue assay includes a colorimetric growth indicator based on detection of metabolic activity. Specifically, the system incorporates an oxidation-reduction (REDOX) indicator that fluoresces and changes color in response to chemical reduction of growth medium resulting from cell growth: the method monitors the reducing environment of proliferating cells; the cell permeable resazurin is added (nonfluorescent form, blue color) and, upon entering cells, is reduced to resorufin (fluorescent form, red color) as result of cellular metabolic activity. Evaluation was performed by adding $20 \mu \mathrm{L}$ of AlamarBlue and incubating at $26{ }^{\circ} \mathrm{C}$ for $24 \mathrm{~h}$. The reducing environment was evaluated after 24 hours by absorbance measurement at the Multiskan Ascent Plate Reader (Thermo Fisher Scientific Inc.) at $550 \mathrm{~nm}$ and $630 \mathrm{~nm}$.

5.4.4. Antiamastigote assay. Human acute monocytic leukemia cell line (THP1) were infected with L. donovani promastigotes for the assessment of the activity of compounds against the amastigote form of Leishmania parasite. Cells were seeded in a 96-well plate $\left(10^{5}\right.$ cells $\left./ \mathrm{mL}\right)$ in complete RPMI-1640 medium and PMA (0.1 $\mu \mathrm{M}$, Cayman Chemical Company, Ann Arbor, Michigan, USA) was added for the cells adherence. Cells were incubated at $37{ }^{\circ} \mathrm{C}$ in a $5 \% \mathrm{CO}_{2}$ incubator. After $48 \mathrm{~h}$, the medium was replaced with fresh medium containing stationary phase promastigotes that were then phagocytized by monocytic cells and transformed into intracellular amastigotes. After $24 \mathrm{~h}$ of incubation, chalcone compounds were added and the plates were incubated at $37^{\circ} \mathrm{C}$ in a $5 \% \mathrm{CO}_{2}$ incubator for 72 h. After incubation, wells were washed, fixed, and stained with Giemsa. Staining was detected using a Nikon Eclipse E200 light microscope (Nikon, Tokyo, Japan). The infectivity index (\% of infected macrophages $\mathrm{x}$ average number of amastigotes per macrophage) was determined by counting at least 100 cells in duplicate cultures.

5.4.5. Citotoxicity test. Mammalian kidney epithelial cells (Vero cell line) were seeded $\left(10^{5} / \mathrm{mL}\right)$ with complete MEM medium in 96-well plates and incubated with test compounds up to a 
concentration of $600 \mu \mathrm{M}$ at $37{ }^{\circ} \mathrm{C}$ in a $5 \% \mathrm{CO}_{2}$ incubator. Similarly, THP1 were seeded in a 96 -well plate $\left(10^{5}\right.$ cells $\left./ \mathrm{mL}\right)$ in complete RPMI-1640 medium and PMA $(0.1 \mu \mathrm{M})$ was added for the cells adherence. After $72 \mathrm{~h}$ of incubation, $20 \mu \mathrm{L}$ of AlamarBlue reagent was added to each well and incubated at $37{ }^{\circ} \mathrm{C}$ for $24 \mathrm{~h}$. Reduction of resazurin to resorufin was evaluated after $24 \mathrm{~h}$ by absorbance measurement at the Multiskan Ascent Plate Reader (Thermo Fisher Scientific Inc.,) at $550 \mathrm{~nm}$ and $630 \mathrm{~nm}$. DMSO was also tested on Leishmania promastigotes and no toxicity was detected. Thus, DMSO did not influence the toxicity of the compounds. Each experiment was performed in duplicate. The selectivity index (SI) for each compound was calculated as the ratio between cytotoxicity $\left(\mathrm{CC}_{50} / 72 \mathrm{~h}\right)$ in Vero cells and activity $\left(\mathrm{IC}_{50} / 72 \mathrm{~h}\right)$ against Leishmania promastigotes.

\subsection{Surface Plasmon Resonance (SPR) measurements}

SPR experiments were carried out using a SensiQ Pioneer system (SensiQ, ICxNomadics Inc.).

The sensor chips (COOH5 SensiQ) were chemically activated by injection of $250 \mu$ of a 1:1 mixture of N-hydroxysuccinimide $(50 \mathrm{mM})$ and N-ethyl-N-(3-dimethylaminopropyl)carbodiimide (200 mM) at a flow rate of $25 \mu 1 / \mathrm{min}$. Recombinant $L i$ TR was immobilized on the activated sensor chip via amine coupling. The reaction was carried out at a rate of $10 \mathrm{~mL} / \mathrm{min}$ in $20 \mathrm{mM}$ sodium acetate at $\mathrm{pH} 4.5$; the remaining $\mathrm{N}$-hydroxysuccinimide esters were blocked by injecting $100 \mu \mathrm{L}$ of $1 \mathrm{M}$ ethanolamine hydrochloride. Recombinant $L i$ TR was captured to approximately $2000 \mathrm{RU}$. The chalcone compounds (analytes) were dissolved at a concentration of $10 \mathrm{mM}$ or $20 \mathrm{mM}$ in dimethylsulfoxide (DMSO), and diluted 1:100 in HEPES-buffered saline (HBS: 10 mM HEPES, pH 7.4; 150 mM NaCl; $0.005 \%$ surfactant P20).

FastStep injections of samples (100 $\mu \mathrm{M}$ analytes in HBS $+1 \%$ DMSO), and reference buffer (HBS + 1\% DMSO) were performed: either the inhibitor and reference buffer were automatically diluted in HBS and injected by 7 serial doubling steps (step contact time $=15 \mathrm{~s}$, nominal flow rate $=$ $200 \mu \mathrm{l} / \mathrm{min}$ ). The following analytes were injected: $0-17 \mathrm{~s}$ : analyte concentration=1.56 $\mu \mathrm{M} ; 17-33 \mathrm{~s}$ : $3.12 \mu \mathrm{M} ; 33-48$ s: $6.25 \mu \mathrm{M} ; 48-62$ s: $12.5 \mu \mathrm{M} ; 63-78$ s: $25 \mu \mathrm{M} ; 78-93$ s: $50 \mu \mathrm{M}$; 94-100 s: $100 \mu \mathrm{M}$; 
751 for each injection, a maximal RU value was obtained. In control experiments, the sensor chip was treated as described above in the absence of immobilized protein. The interaction of the immobilized protein with the analytes was detected by mass concentration dependent changes of the refractive index on the sensor chip surface. The changes in the observed SPR signal are expressed as Resonance Units (RU). Typically, a response change of $1000 \mathrm{RU}$ corresponds to a change in the surface concentration on the sensor chip of about $1 \mathrm{ng}$ of protein per $\mathrm{mm}^{2}$. The increase in RU relative to baseline indicates complex formation between the immobilized protein and the analytes. For each concentration, the plateau region represents the steady-state phase of the interaction. The decrease in RU after $100 \mathrm{~s}$ indicates analyte dissociation from the immobilized ligand after buffer injection.

Each sensorgram is the average of three different experiments. Sensorgrams were subjected to global analysis using QDat software 2.2.0.23; for each analyte concentration a \% Response was calculated, allowing a local Rmax fit (according to the molecular weight of each compound) and displaying as a response relative to the Rmax. \% Response vs. analyte concentration was plotted, and $K_{D}$ values were calculated for each analyte both from Scatchard plots and from global analysis using the QDat software, by fitting a simple 1:1 binding model to the data.

\subsection{Enzymatic assay}

LiTR was cloned and purified as previously described by Baiocco et al. [13] [35]. Enzyme inhibition assays were carried out at $25{ }^{\circ} \mathrm{C}$ using a diode array Hewlett-Packard HP8452A spectrophotometer. The solution containing TR $40 \mathrm{nM}, \mathrm{TS}_{2}(75 \mu \mathrm{M}, 100 \mu \mathrm{M}, 200 \mu \mathrm{M}, 400 \mu \mathrm{M})$ and chalcone compound $6(30 \mathrm{nM}, 50 \mathrm{nM}, 70 \mathrm{nM}, 1 \mu \mathrm{M})$ were allowed to equilibrate for $2 \mathrm{~min}$ in a quartz cuvette. Assays were initiated by addition of NADPH $40 \mu \mathrm{M}$ and the absorbance decrease at $340 \mathrm{~nm}$, which indicates the oxidation of NADPH, was followed. The concentrations of NADPH was calculated using the molar extinction coefficient $\varepsilon=6,222 \mathrm{M}^{-1} \mathrm{~cm}^{-1}$ at $340 \mathrm{~nm}$. Trypanothione disulfide (Bachem) and NADPH (Sigma) were used for the experiments.

\subsection{Docking experiments}


The pdb coordinates of Compound 6 were designed using the WebGL server [36]. Docking 778 calculations were performed by the Autodock 4.0 software [37]. Docking procedures were 779 performed using the structures of TR in both the oxidized form (PDB code: 2JK6) and the reduced 780 form (PDB code 4ADW) downloaded from the protein data bank (PDB code: 2JK6). The TR 781 structure was edited using the software from the ADT package to remove all water molecules and 782 add hydrogen atoms. Non-polar hydrogens and lone pairs were then merged and each atom within 783 the macromolecule was assigned a Gasteiger partial charge. A grid box of $80 \times 80 \times 80$ points, with 784 a spacing of $0.375 \AA$, was positioned at the active-site gorge. The Lamarckian genetic algorithm 785 (LGA) was employed with the maximum number of generations and energy evaluations of 631 and 7861000334 , respectively.

\section{Acknowledgments}

788 This work was supported by Fondazione Del Monte di Bologna e Ravenna (Prot. Nr. 349 789 bis/2016), by the University of Bologna (RFO funds) and by the Ministry of Education (PRIN 2015, 790 Prot. 20154JRJPP). We would like to thank Dr. David Staid for his help to conceive the docking 791 experiments. 
<smiles>C=CC(C)(C)c1cc(/C=C/C(=O)c2ccc(O)cc2)c(OC)cc1O</smiles><smiles>CC(C)=CCc1c(O)ccc(C(=O)/C=C/c2ccccc2)c1O</smiles><smiles>[R]Oc1cc(OCC=C(C)C)ccc1C(=O)/C=C/c1cc2ccc1CCCCC2</smiles><smiles></smiles>

9-16, 25-31

Figure 1. Structures of licochalcone $A$, isocordoin and general structure of the newly synthesized 797 compounds (Series 1 and 2).

a

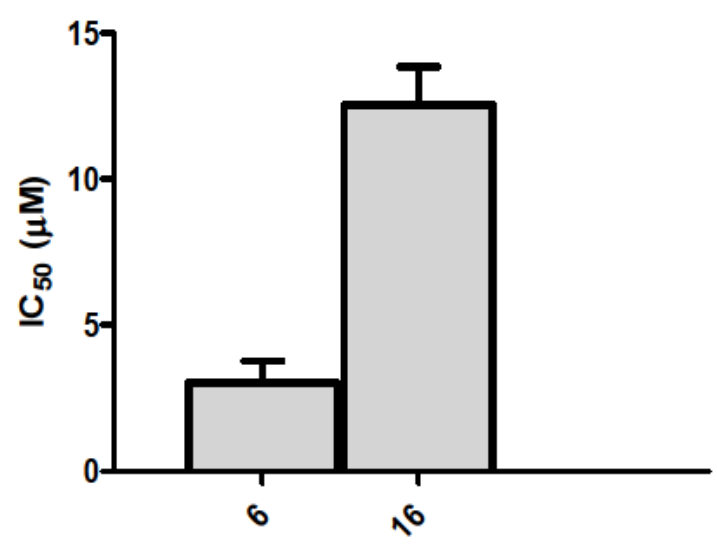

Anti-Promastigotes

798

b

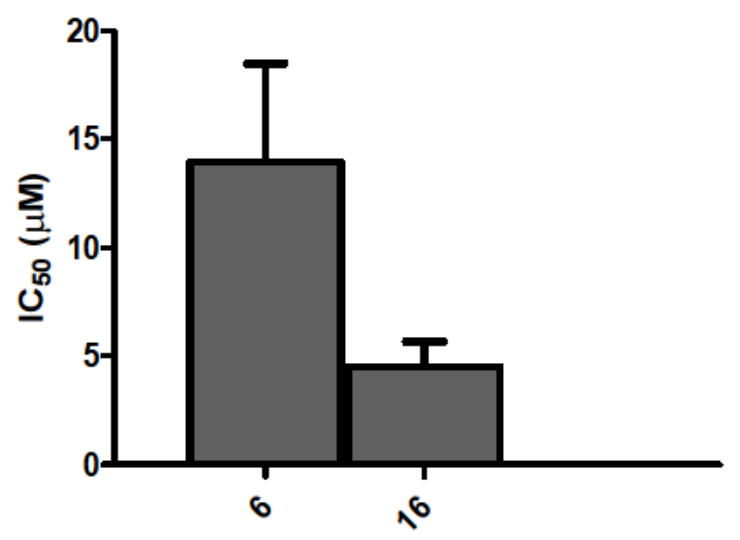

Figure 2. Antipromastigote (2a) and antiamastigote (2b) activity of compound 6 and compound 16. L. donovani promastigotes were treated with tested compounds at a concentration range of $40-1.5$ $\mu \mathrm{M}$ for $72 \mathrm{~h}$, then the effect of the chalcones was evaluated by the AlamarBlue ${ }^{\circledR}$ assay. For the amastigote assay, Leishmania-infected THP-1 cells were treated with tested compounds at a 
concentration range of 40-1.5 $\mu \mathrm{M}$ for $72 \mathrm{~h}$, then fixed and stained with Giemsa. Results from three independent experiments performed in duplicates are shown. $\mathrm{IC}_{50} / 72 \mathrm{~h}$, as concentration of compound required to inhibit growth by $50 \%$, is plotted in y axis. Bars represent mean values \pm standard errors.

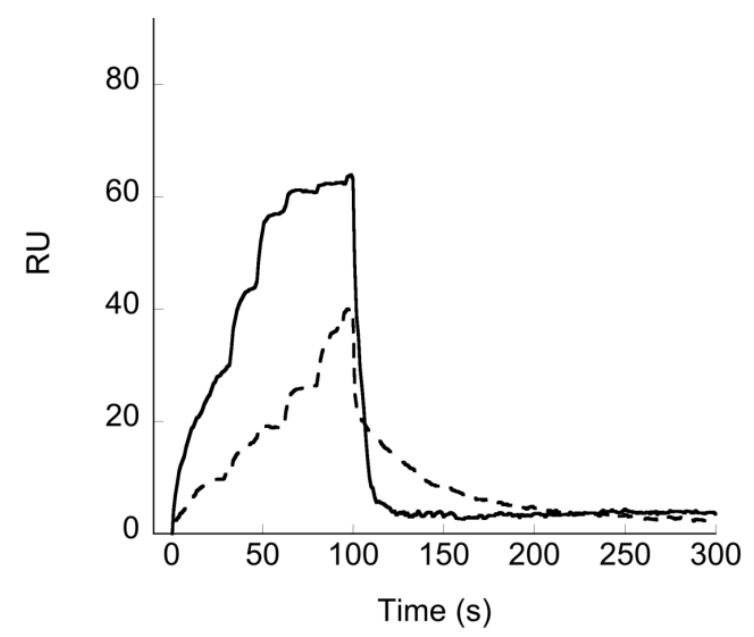

Figure 3. SPR binding curves (sensorgrams) obtained by injecting different concentrations (range 1.5-100 $\mu \mathrm{M}$ ) of compounds $\mathbf{6}$ (full line) and $\mathbf{1 6}$ (dashed line) on a surface of covalently immobilized TR; dissociations phases are also shown. RU; response units.

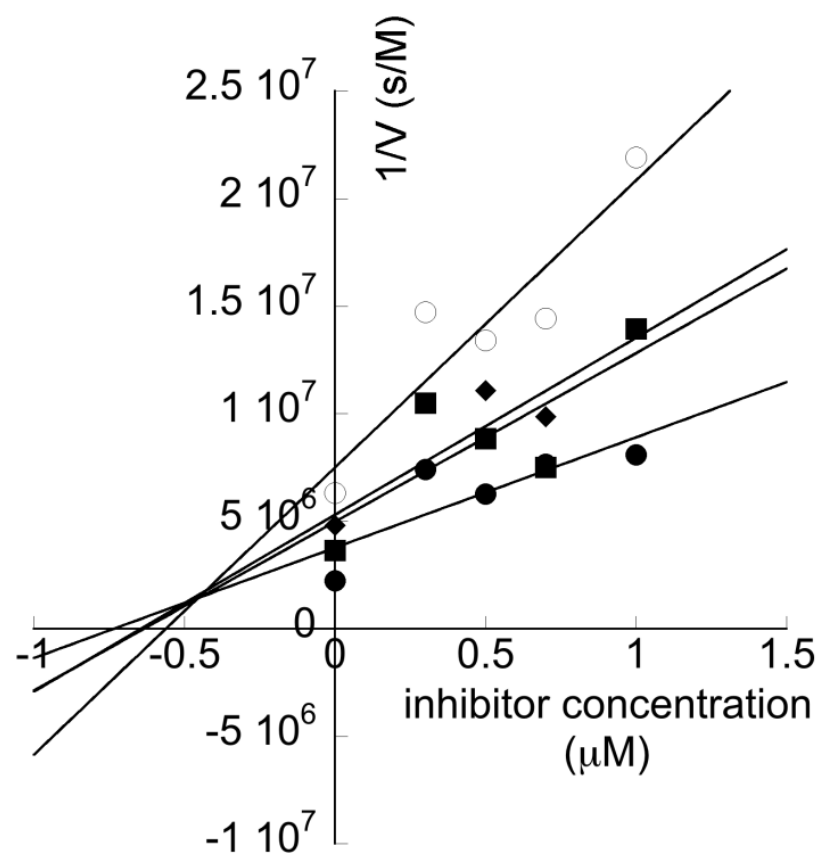

Figure 4 Dixon plot of TR inhibition by compound 6 (concentration range: 0-1.0 $\mu \mathrm{M}$ ). Open circles $\left[\mathrm{TS}_{2}\right]=75 \mu \mathrm{M}$; filled squares $\left[\mathrm{TS}_{2}\right]=100 \mu \mathrm{M}$; filled diamonds $\left[\mathrm{TS}_{2}\right]=200 \mu \mathrm{M}$ and filled circles $\left[\mathrm{TS}_{2}\right]=400 \mu \mathrm{M}$. 


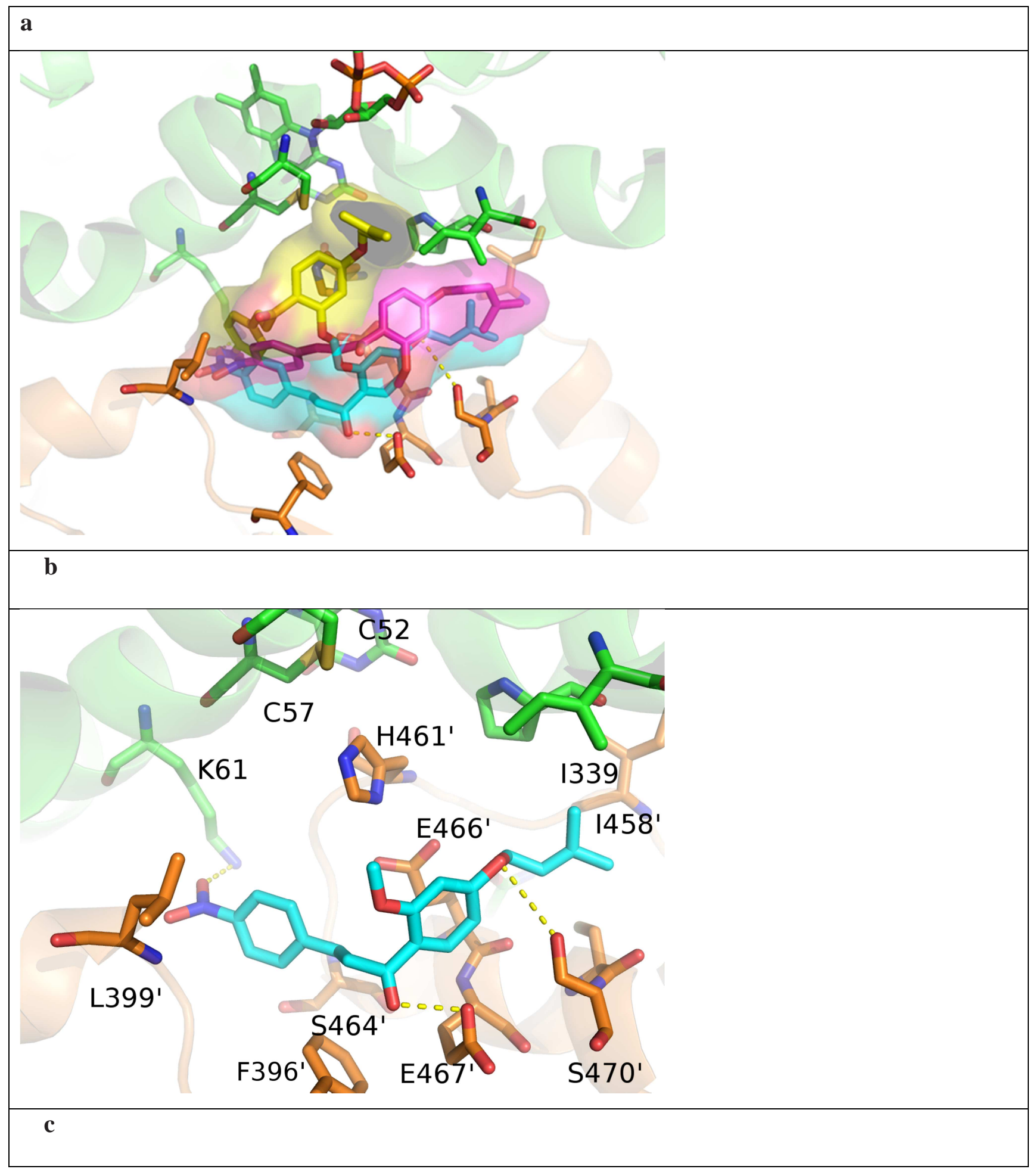

35 


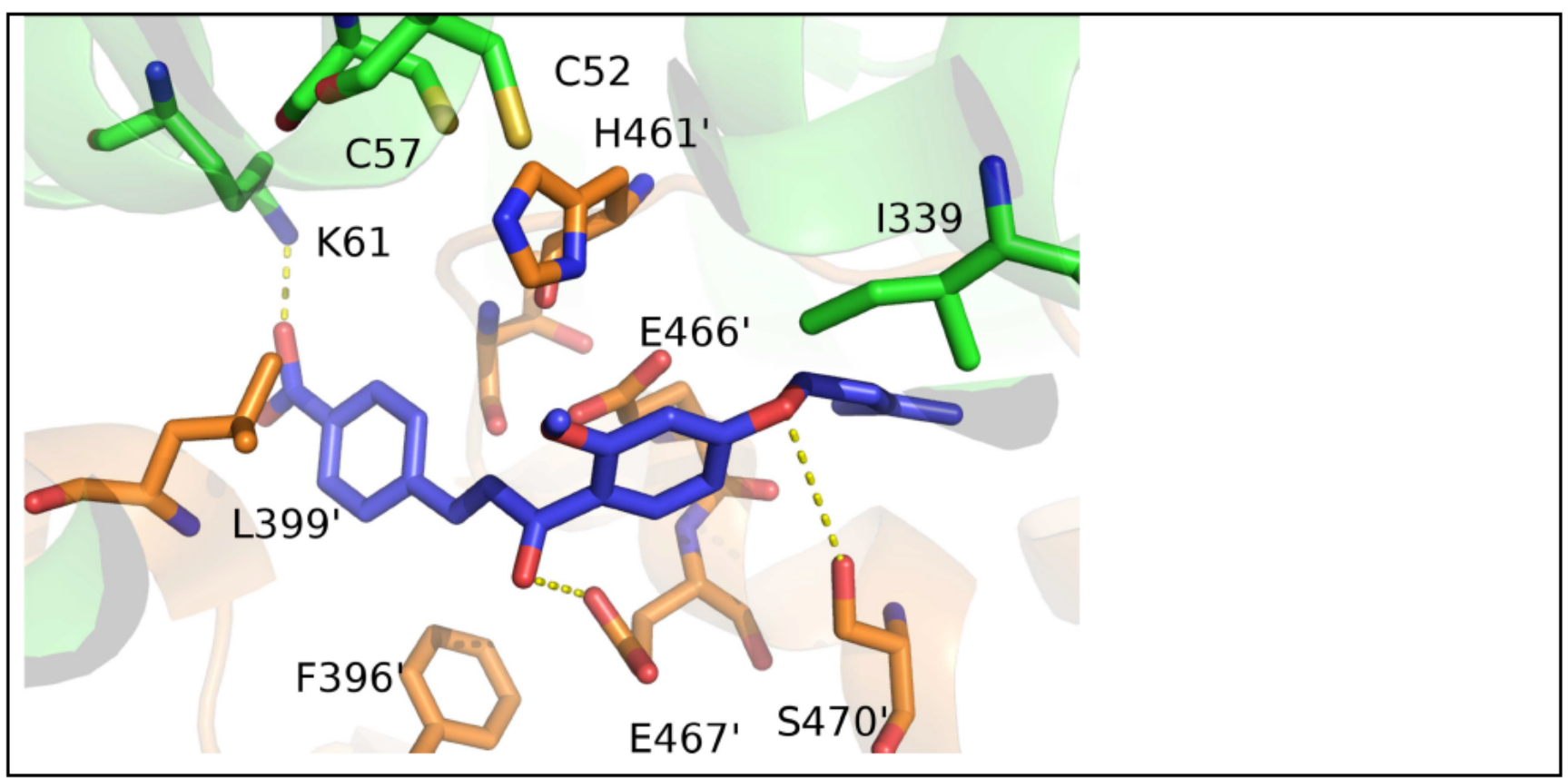

Figure 5. Blow up of the complex between compound 6 and TR obtained by docking experiments using both the oxidized form (PDB code: 2JK6) ( $a$ and $b$ ) and the reduced form (PDB code 4ADW) (c) of the protein. a. In A are represented the lowest energy poses belonging to the most populated clusters (reported in TableS1). The pose 3 belonging to cluster 1 is colored pink; the pose 60 belonging to cluster 2 is colored cyan; the pose 94 belonging to cluster 3 is colored yellow. b. In b, the pose of compound 6 docked in the oxidized form of TR belonging to the most populated cluster (pose 60 belonging to cluster 2) is represented. c. In c, the pose of compound 6 docked in the reduced form of TR belonging to the most populated cluster (pose 61 belonging to cluster 3 ) is represented. Compound 6 and the residues interacting with it are indicated and represented as sticks. The two TR subunits are colored in green and orange whereas compound $\mathbf{6}$ docked in the oxidized TR is colored cyan and compound $\mathbf{6}$ docked in reduced TR is colored blue. The picture was obtained using PyMOL (The PyMOL Molecular Graphics System, Version 2.0 Schrödinger, LLC.)<smiles>[R]Oc1ccc(C(C)=O)c(O)c1</smiles><smiles>[R]Oc1ccc(C(=O)/C=C/[Bi])c(O)c1</smiles>

$1,2,9,19$<smiles>CC(=O)Oc1cc(OCC=C(C)C)ccc1C(=O)C=Cc1ccccc1</smiles>

20

Scheme 1. Synthetic route of compounds $1-37^{\mathrm{a}}$

${ }^{a}$ Reagents and conditions: a) selected alkyl bromide, $\mathrm{K}_{2} \mathrm{CO}_{3}$, acetone, reflux; b) $\mathrm{KOH} 50 \%$, EtOH, rt, $18 \mathrm{~h}$; c) acetic anhydride, reflux. 
Table 1. Inhibitory activity of chalcones 1-31 against promastigotes of $L$. donovani growth, 839 cytotoxicity in mammalian kidney epithelial cells and in a human monocytic cell line and selectivity 840 indexes.

\begin{tabular}{|c|c|c|c|c|c|c|}
\hline Comp & Structure & $\begin{array}{c}\text { L.donov } \\
\text { IC }_{50} \\
(\mu \mathrm{M})^{\mathrm{a}}\end{array}$ & $\begin{array}{l}\text { Vero } \\
\text { CC }_{50} \\
(\mu M)^{b}\end{array}$ & $S I^{\mathbf{c}, \mathbf{d}}$ & $\begin{array}{c}\text { THP-1 } \\
\mathrm{CC}_{50} \\
(\mu \mathrm{M})\end{array}$ & $\mathrm{SI}^{\mathrm{c}, \mathrm{e}}$ \\
\hline 1 & & 5.0 & 40.0 & 8 & 16.0 & 3.2 \\
\hline 2 & & 8.5 & 210.0 & 24.7 & 100.0 & 11.8 \\
\hline 3 & & 10.5 & 16.0 & 1.5 & 16.0 & 1.5 \\
\hline 4 & & 10.5 & 22.0 & 2 & 40.0 & 3.8 \\
\hline 5 & & 16.0 & 600.0 & 37.5 & 100.0 & 6.3 \\
\hline 6 & & 3.0 & 600.0 & 200 & 600.0 & 200 \\
\hline 7 & & 15.0 & 50.0 & 3.3 & 50.0 & 3.3 \\
\hline 8 & & 11.0 & 40.0 & 3.6 & 25.0 & 2.3 \\
\hline 9 & & 17.5 & 40.0 & 2.3 & 25.0 & 1.4 \\
\hline 10 & & 4.0 & 20.0 & 5 & 16.0 & 4 \\
\hline 11 & & 9.5 & 15.0 & 1.6 & 16.0 & 1.7 \\
\hline
\end{tabular}




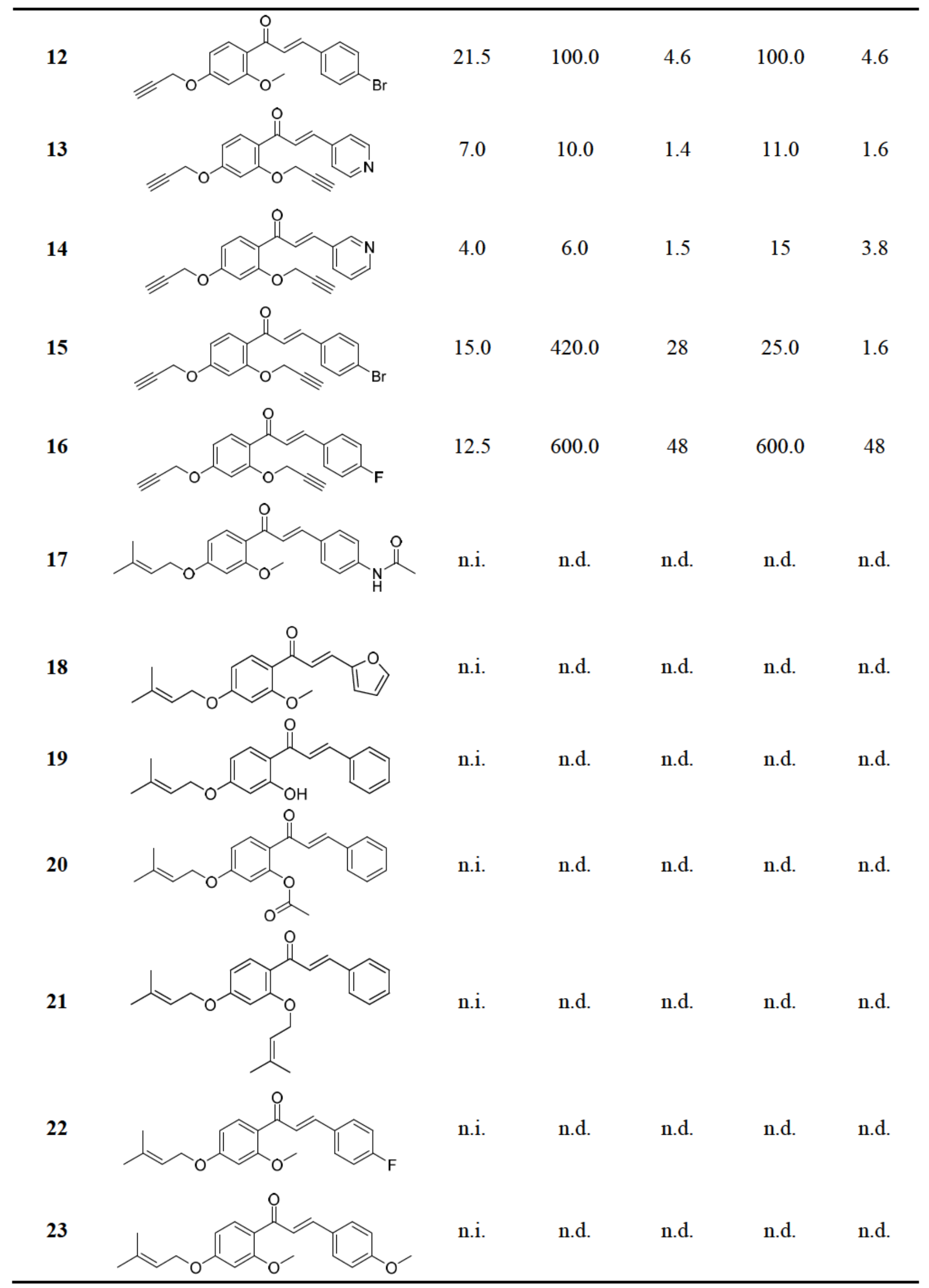


24<smiles>COc1ccc(/C=C/C(=O)c2ccc(OCC=C(C)C)cc2OC)cc1OC</smiles>

25<smiles>C#CCOc1ccc(C(=O)/C=C/c2ccc([N+](=O)[O-])cc2)c(OC)c1</smiles>

26<smiles>C#CCOc1ccc(C(=O)/C=C/c2ccc([N+](=O)[O-])cc2)c(OCC#C)c1</smiles>

n.i.

i.

n.d.

n.d.

n.d.

n.d.

n.d.

n.d.<smiles>C#CCOc1ccc(C(=O)/C=C/c2cc(OC)c3c(c2)OCCO3)c(OC)c1</smiles>
n.i.
n.d.
n.d.
n.d.
n.d.

28<smiles>C#CCOc1ccc(C(=O)/C=C/c2ccc(OC)c(OC)c2)c(OC)c1</smiles>

29<smiles>C#CCOc1ccc(C(=O)/C=C/c2ccc(OC)c(OC)c2)c(OCC#C)c1</smiles><smiles>C#CCOc1ccc(C(=O)/C=C/c2cc(OC)c(OC)c(OC)c2)c(OCC#C)c1</smiles>

31<smiles>C#CCOc1ccc(C(=O)/C=C/c2ccc(OC)cc2)c(OCC#C)c1</smiles>

30 n.d.

n.d.

n.d.

n.d.

n.d.

n.d.

n.d.

n.d.
n.i.
n.d.
n.d.
n.d.
n.d.

n.i.

n.d.

n.d.

n.d.

n.d.

Amph

B

0.

200.0

666

200.0

666

${ }^{\mathrm{a}} \mathrm{IC}_{50} / 72 \mathrm{~h}$ represents concentration of a compound that causes $50 \%$ growth inhibition and is the mean of two independent determinations. The experimental error was within $50 \%$. ${ }^{\mathrm{b}} \mathrm{CC}_{50} / 72 \mathrm{~h}$ represents $50 \%$ cytotoxic concentration. ${ }^{\mathrm{c}} \mathrm{SI}$; Selectivity index $\left(\mathrm{SI}=\mathrm{CC}_{50} / \mathrm{IC}_{50}\right)$. ${ }^{\mathrm{d}} \mathrm{SI}$ was calculated considering $\mathrm{CC}_{50}$ on Vero cells. ${ }^{\mathrm{e}} \mathrm{SI}$ was calculated considering $\mathrm{CC}_{50}$ on THP1 cells. Comp; compounds. n.i.; not inhibiting parasite growth up to $40 \mu \mathrm{M}$. n.d.; not determined due to the low antileishmanial potency. Amph B; amphotericin B. 
850 [1] D. Pace, Leishmaniasis, J. Infect., 69 Suppl 1 (2014) S10-18.

851 [2] WHO, Control of the leishmaniases: report of a meeting of the WHO Expert Committee on the 852 Control of Leishmaniases, Geneva, 22-26 March 2010, in: WHO technical report series, 2010.

853 [3] D. Savoia, Recent updates and perspectives on leishmaniasis, J. Infect. Dev. Ctries, 9 (2015) $854588-596$.

855 [4] P.J. Hotez, B. Pecoul, "Manifesto" for advancing the control and elimination of neglected 856 tropical diseases, PLoS Negl. Trop. Dis., 4 (2010) e718.

857 [5] J.F. Barbosa, S.M. de Figueiredo, F.M. Monteiro, F. Rocha-Silva, C. Gaciele-Melo, S.S. 858 Coelho, S. Lyon, R.B. Caligiorne, New Approaches on Leishmaniasis Treatment and Prevention: A 859 Review of Recent Patents, Recent Pat. Endocr. Metab. Immune Drug Discov., 9 (2015) 90-102.

860 [6] R.K. Jha, A.K. Sah, D.K. Shah, P. Sah, The treatment of visceral leishmaniasis: safety and 861 efficacy, JNMA J. Nepal Med. Assoc., 52 (2013) 645-651.

862 [7] D. Smirlis, M.B. Soares, Selection of molecular targets for drug development against 863 trypanosomatids, Sub-cellular biochemistry, 74 (2014) 43-76.

864 [8] S. Muller, E. Liebau, R.D. Walter, R.L. Krauth-Siegel, Thiol-based redox metabolism of 865 protozoan parasites, Trends in parasitology, 19 (2003) 320-328.

866

867

868

869

870

871

872

873

[9] K. Augustyns, K. Amssoms, A. Yamani, P.K. Rajan, A. Haemers, Trypanothione as a target in the design of antitrypanosomal and antileishmanial agents, Curr. Pharm. Des., 7 (2001) 1117-1141. [10] A. Ilari, A. Fiorillo, P. Baiocco, E. Poser, G. Angiulli, G. Colotti, Targeting polyamine metabolism for finding new drugs against leishmaniasis: a review, Mini Rev. Med. Chem., 15 (2015) 243-252.

[11] L.R. Krauth-Siegel, M.A. Comini, T. Schlecker, The trypanothione system, Sub-cellular biochemistry, 44 (2007) 231-251.

[12] A. Ilari, A. Fiorillo, I. Genovese, G. Colotti, Polyamine-trypanothione pathway: an update, Future Med. Chem., 9 (2017) 61-77.

[13] P. Baiocco, G. Colotti, S. Franceschini, A. Ilari, Molecular Basis of Antimony Treatment in Leishmaniasis, J. Med. Chem., 52 (2009) 2603-2612.

[14] P. Baiocco, A. Ilari, P. Ceci, S. Orsini, M. Gramiccia, T. Di Muccio, G. Colotti, Inhibitory Effect of Silver Nanoparticles on Trypanothione Reductase Activity and Leishmania infantum Proliferation, ACS Med. Chem. Lett., 2 (2011) 230-233.

[15] A. Ilari, P. Baiocco, L. Messori, A. Fiorillo, A. Boffi, M. Gramiccia, T. Di Muccio, G. Colotti, A gold-containing drug against parasitic polyamine metabolism: the X-ray structure of trypanothione reductase from Leishmania infantum in complex with auranofin reveals a dual mechanism of enzyme inhibition, Amino acids, 42 (2012) 803-811.

[16] G. Colotti, A. Ilari, A. Fiorillo, P. Baiocco, M.A. Cinellu, L. Maiore, F. Scaletti, C. Gabbiani, L. Messori, Metal-based compounds as prospective antileishmanial agents: inhibition of trypanothione reductase by selected gold complexes, ChemMedChem, 8 (2013) 1634-1637.

[17] P. Baiocco, G. Poce, S. Alfonso, M. Cocozza, G.C. Porretta, G. Colotti, M. Biava, F. Moraca, M. Botta, V. Yardley, A. Fiorillo, A. Lantella, F. Malatesta, A. Ilari, Inhibition of Leishmania infantum trypanothione reductase by azole-based compounds: a comparative analysis with its physiological substrate by X-ray crystallography, ChemMedChem, 8 (2013) 1175-1183.

[18] F. Saccoliti, G. Angiulli, G. Pupo, L. Pescatori, V.N. Madia, A. Messore, G. Colotti, A. Fiorillo, L. Scipione, M. Gramiccia, T. Di Muccio, R. Di Santo, R. Costi, A. Ilari, Inhibition of Leishmania infantum trypanothione reductase by diaryl sulfide derivatives, J. Enzyme Inhib. Med. Chem., 32 (2017) 304-310.

[19] I.A. Rodrigues, A.M. Mazotto, V. Cardoso, R.L. Alves, A.C. Amaral, J.R. Silva, A.S. Pinheiro, A.B. Vermelho, Natural Products: Insights into Leishmaniasis Inflammatory Response, Mediators Inflamm., 2015 (2015) 835910. 
[20] A. Oryan, Plant-derived compounds in treatment of leishmaniasis, Iran J. Vet. Res., 16 (2015) $1-19$.

[21] B.E. Evans, K.E. Rittle, M.G. Bock, R.M. DiPardo, R.M. Freidinger, W.L. Whitter, G.F. Lundell, D.F. Veber, P.S. Anderson, R.S. Chang, et al., Methods for drug discovery: development of potent, selective, orally effective cholecystokinin antagonists, J. Med. Chem., 31 (1988) 22352246.

[22] N.K. Sahu, S.S. Balbhadra, J. Choudhary, D.V. Kohli, Exploring pharmacological significance of chalcone scaffold: a review, Curr. Med. Chem., 19 (2012) 209-225.

[23] J.R. Dimmock, D.W. Elias, M.A. Beazely, N.M. Kandepu, Bioactivities of chalcones, Curr. Med. Chem., 6 (1999) 1125-1149.

[24] M. Liu, P. Wilairat, S.L. Croft, A.L. Tan, M.L. Go, Structure-activity relationships of antileishmanial and antimalarial chalcones, Bioorg. Med. Chem., 11 (2003) 2729-2738.

[25] R. Shivahare, V. Korthikunta, H. Chandasana, M.K. Suthar, P. Agnihotri, P. Vishwakarma, T.K. Chaitanya, P. Kancharla, T. Khaliq, S. Gupta, R.S. Bhatta, J.V. Pratap, J.K. Saxena, S. Gupta, N. Tadigoppula, Synthesis, structure-activity relationships, and biological studies of chromenochalcones as potential antileishmanial agents, J. Med. Chem., 57 (2014) 3342-3357.

[26] R. Borges-Argaez, T. Vela-Catzin, A. Yam-Puc, M.J. Chan-Bacab, R.E. Moo-Puc, M. Caceres-Farfan, Antiprotozoal and Cytotoxic Studies on Some Isocordoin Derivatives, Planta Med, 75 (2009) 1336-1338.

[27] H. Hussain, A. Al-Harrasi, A. Al-Rawahi, I.R. Green, S. Gibbons, Fruitful decade for antileishmanial compounds from 2002 to late 2011, Chem. Rev., 114 (2014) 10369-10428.

[28] N. Singh, B.B. Mishra, S. Bajpai, R.K. Singh, V.K. Tiwari, Natural product based leads to fight against leishmaniasis, Bioorg. Med. Chem., 22 (2014) 18-45.

[29] S. Gupta, R. Shivahare, V. Korthikunta, R. Singh, N. Tadigoppula, Synthesis and biological evaluation of chalcones as potential antileishmanial agents, Eur. J. Med. Chem., 81 (2014) 359-366. [30] P. Boeck, C.A. Bandeira Falcão, P.C. Leal, R.A. Yunes, V.C. Filho, E.C. Torres-Santos, B. Rossi-Bergmann, Synthesis of chalcone analogues with increased antileishmanial activity, Bioorg. Med. Chem., 14 (2006) 1538-1545.

[31] E.C. Torres-Santos, M.I. Sampaio-Santos, F.S. Buckner, K. Yokoyama, M. Gelb, J.A. Urbina, B. Rossi-Bergmann, Altered sterol profile induced in Leishmania amazonensis by a natural dihydroxymethoxylated chalcone, J. Antimicrob. Chemother., 63 (2009) 469-472.

[32] M. Chen, S.B. Christensen, T.G. Theander, A. Kharazmi, Antileishmanial activity of licochalcone A in mice infected with Leishmania major and in hamsters infected with Leishmania donovani, Antimicrob. Agents Chemother., 38 (1994) 1339-1344.

[33] S. Krieger, W. Schwarz, M.R. Ariyanayagam, A.H. Fairlamb, R.L. Krauth-Siegel, C. Clayton, Trypanosomes lacking trypanothione reductase are avirulent and show increased sensitivity to oxidative stress, Mol. Microbiol., 35 (2000) 542-552.

[34] M.C. do Nascimento, W.B. Mors, Chalcones of the root bark of Derris sericea, Phytochemistry, 11 (1972) 3023-3028.

[35] P. Baiocco, S. Franceschini, A. Ilari, G. Colotti, Trypanothione reductase from Leishmania infantum: cloning, expression, purification, crystallization and preliminary X-ray data analysis, Protein Pept. Lett., 16 (2009) 196-200.

[36] S. Yuan, H.C.S. Chan, Z. Hu, Implementing WebGL and HTML5 in Macromolecular Visualization and Modern Computer-Aided Drug Design, Trends in biotechnology, 35 (2017) 559571.

[37] G.M. Morris, R. Huey, W. Lindstrom, M.F. Sanner, R.K. Belew, D.S. Goodsell, A.J. Olson, AutoDock4 and AutoDockTools4: Automated docking with selective receptor flexibility, Journal of computational chemistry, 30 (2009) 2785-2791. 
- The development of new, effective and safe antileishmanial drugs is urgently needed.

- The enzyme trypanothione reductase, by disrupting Leishmania parasite redox balance. represents a validated molecular target for the development of antiparasitic agents.

- Chalcone as useful template for the design of novel antileishmanial compounds.

- 16 of the newly synthetized chalcones were active against L.donovani in vitro.

- Chalcone 6 potently inhibits leishmanial trypanothione reductase. 